\title{
Geologia, Petrografia e Geoquímica do Batólito Seringa, Província Carajás, SSE do Pará
}

\author{
Antonio Lima de Paiva Júnior ${ }^{1,2}$, Claudio Nery Lamarão ${ }^{1,3}$ \\ \& Paulo Henrique Araújo Lima ${ }^{1,4}$
}

\begin{abstract}
Resumo O Granito Seringa, com cerca de $2250 \mathrm{~km}^{2}$ de superfície aflorante, representa o maior batólito da Província Carajás. É intrusivo em unidades arqueanas do Terreno Granito-Greenstone de Rio Maria, sudeste do Cráton Amazônico. É constituído por dois grandes conjuntos petrográficos: a) rochas monzograníticas, representadas por bitotita-anfibólio monzogranito grosso (BAMGrG) e anfibólio-bitotita monzogranito grosso (ABMGrG); b) rochas sienograníticas, representadas por anfibólio-biotita sienogranito porfirítico (ABSGrP), leucosienogranito heterogranular (LSGrH), leucomicrosienogranito (LMSGr) e anfibólio-biotita sienogranito heterogranular $(\mathrm{ABSGrH})$. Biotita e anfibólio são os minerais varietais e zircão, apatita, minerais opacos e allanita, os acessórios. O Granito Seringa mostra caráter subalcalino, metaluminoso a fracamente peraluminoso e possui altas razões $\mathrm{FeO}_{\mathrm{t}} / \mathrm{FeO}_{\mathrm{t}}+\mathrm{MgO}(0,86 \mathrm{a} 0,97)$ e $\mathrm{K}_{2} \mathrm{O} / \mathrm{Na}_{2} \mathrm{O}$ (1 a 2). Os ETR mostram padrão de fracionamento moderado para os ETRL e sub-horizontalizado para os ETRP. As anomalias negativas de Eu são fracas nas rochas monzograníticas e moderadas a acentuadas nas sienograníticas e leucomonzograníticas, respectivamente, com exceção dos ABSGrP. Mostra afinidades geoquímicas com granitos intraplacas ricos em ferro, do subtipo A2 e do tipo A oxidados. As relações de campo e os aspectos petrográficos e geoquímicos não são coerentes com a evolução das fácies do Granito Seringa a partir da cristalização fracionada de um mesmo pulso magmático. $\mathrm{O}$ Granito Seringa apresenta maiores semelhanças petrográficas, geoquímicas e de suscetibilidade magnética com as rochas da Suíte Serra dos Carajás, podendo ser enquadrado nesta importante suíte granitoide.
\end{abstract}

Palavras-chave: Paleoproterozoico, Cráton amazônico, Granito Seringa, Tipo A oxidado.

\begin{abstract}
Geology, Petrography and Geochemistry of the Seringa Batholith, Carajás Province, SSE of the Pará. The Seringa Granite, with $2250 \mathrm{~km}^{2}$ of outcropping area represents the biggest granite batholith of the Carajás Province. It is intrusive in Archean units of the Rio Maria Granite-Greenstone Terrane, located in the southeastern of the Amazonian Craton. The Seringa Granite is formed by two great petrographic groups: A) monzogranite rocks, represented by biotite-amphibole coarse-grained monzogranite, amphibolebiotite coarse-grained monzogranite; B) syenogranite rocks, represented by, porphyry amphibole-biotite syenogranite, heterogranular leuco-syenogranite, leuco-microsyenogranite, and heterogranular amphibolebiotite syenogranite. Biotite and amphibole are the varietal minerals and zircon, apatite, opaque, and allanite the accessories minerals. The Seringa Granite is subalkaline, metaluminous to peraluminous, display $\mathrm{K}_{2} \mathrm{O} /$ $\mathrm{Na}_{2} \mathrm{O}$ ratios between 1 and 2 and $\mathrm{FeOt} /(\mathrm{FeOt}+\mathrm{MgO})$ between 0.86 and 0.97 . The patterns of REE show increase in negative europium anomalies from the less evolved facies to the more evolved facies. In these sense, it is enriched in light REE parallel to the impoverishment of heavy REE. It shows geochemical affinities with within-plate ferroan granites, of the A2-subtype and oxidized A-type granites. The field relations and the petrographic and geochemical features of the Seringa Granite are not consistent with the evolution of its facies from a single magma pulse by fractional crystallization. The Seringa Granite show petrographic, geochemical and magnetic susceptibility properties that suggest its inclusion in the Serra dos Carajás Suite.
\end{abstract}

Keywords: Paleoproterozoic, Amazonian Craton, Seringa Granite, oxidized A-type.

INTRODUÇÃOO O Cráton Amazônico foi, em tempos Proterozoicos, palco de uma das mais extensas atividades graníticas que se têm registro na crosta terrestre (Dall'Agnol et al. 1994). Manifestando-se recorrentemente por quase um bilhão de anos, esse magmatismo anorogênico é representado por rochas plutônicas e vulcânicas diversas, associadas ou não a mineralizações. A Província Carajás (PC), localizada

1 - Grupo de Pesquisa Petrologia de Granitoides, Universidade Federal do Pará, Belém (PA), Brasil.

2 - Estudante do Programa de Pós-Graduação em Geologia e Geoquímica do Instituto de Geociências da Universidade Federal do Pará, Belém (PA), Brasil. E-mail: antoniollima@gmail.com

3 - Programa de Pós-Graduação em Geologia e Geoquímica do Instituto de Geociências da Universidade Federal do Pará, Belém (PA), Brasil.

E-mail: lamarao@ufpa.br

4 - Estudante de Graduação em Geologia do Instituto de Geociências da Universidade Federal do Pará, Belém (PA), Brasil. E-mail:

phlima@ufpa.br 
na porção sudeste deste cráton, é caracterizada por sua grande variedade de recursos minerais, destacando-se os depósitos de ferro, ouro, manganês, níquel e cobre (DOCEGEO 1988). Na PC (Fig. 1) esta granitogênese anorogênica é representada pelas suítes graníticas Jamon, Suíte Serra dos Carajás e Velho Guilherme (Dall'Agnol et al. 2005).

Diversos estudos foram realizados nos granitos que integram a Suíte Jamon, em particular no próprio granito Jamon, onde foram realizados trabalhos experimentais para determinação da temperatura, pressão e fugacidade de $\mathrm{H}_{2} \mathrm{O}$ e de $\mathrm{O}_{2}$ sob as quais o magma Jamon cristalizou (Dall'Agnol et al. 1999c). Os granitos Redenção e Bannach, também pertencentes a esta Suíte, foram estudados sob o ponto de vista petrográfico, geoquímico e geocronológico, tendo sido proposto um modelo de colocação para os mesmos (Oliveira et al. 2006).

O Granito Seringa, embora já tenha sido datado geocronologicamente (Silva et al. 1974, Lafon et al. 1995), ainda carece de estudos petrográficos e geoquímicos detalhados. As abordagens existentes são insuficientes e de cunho regional (Araújo \& Maia. 1991). Embora as três suítes que compõem a PC sejam formadas por granitos tipo A com idades de aproximadamente 1,88 Ga, existem entre elas algumas diferenças importantes com relação à petrografia, geoquímica e susceptibilidade magnética (Dall'Agnol et al. 2005). Portanto, o principal objetivo desta pesquisa foi caracterizar o Granito Seringa no que diz respeito aos seus aspectos geológicos, petrográficos e geoquímicos, a fim de compará-lo com os demais granitos anorogênicos e situá-lo em uma das três suítes da PC. Com a finalização desse trabalho, pretende-se colaborar no avanço da evolução e conhecimento destes granitos, visto que os mesmos são temas de constantes debates na literatura.

CONTEXTO GEOLÓGICO REGIONAL Várias intrusões graníticas marcam o evento final de formação do segmento crustal, hoje representado pela PC. De idade essencialmente arqueana, esse segmento se consolidou em tempos paleoproterozoicos, por volta de 1,88 Ga, quando foi afetado por eventos distensivos, marcados pela intrusão de granitos anorogênicos, dentre os quais se destaca o batólito Seringa. A PC é constituída por três domínios tectonicamente distintos (Dall'Agnol et al. 2005): o Terreno Granito-Greenstone de Rio Maria (TGGRM), o Bloco Carajás (BC) e a Região Xingu (RX). O TGGRM é formado por greenstone belts (Supergrupo Andorinhas) e por quatro grupos de granitoides arqueanos (Pimentel \& Machado 1994, Macambira \& Lafon 1995, Althoff et al. 2000, Leite 2001, Leite et al. 2004, Dall'Agnol et al. 2006, Oliveira et al. 2009): (1) Série tonalítica-trondhjemítica mais antiga (2,98 a 2,93 Ga), representada pelo Tonalito Arco Verde e Complexo Tonalítico Caracol; (2) granitoides dominantemente granodioríticos com alto $\mathrm{Mg}(2,87$ $\mathrm{Ga}$ ), formado pelos granodioritos da Suíte Sanukitoide Rio Maria e rochas intermediárias e máficas associadas; (3) Série tonalítica-trondhjemítica mais jovem
(2,87 a 2,86 Ga), composta pelos Trondhjemitos Água Fria e Mogno; e (4) leucogranitos cálcico-alcalinos potássicos (2,93 a 2,86 Ga), representados pelos granitos Xinguara, Mata Surrão, Guarantã e similares.

$\mathrm{O}$ evento magmático dominante no $\mathrm{BC}$ é representado pelo vulcanismo máfico do Supergrupo Itacaiúnas, além do magmatismo máfico-ultramáfico do Complexo Luanga e de um grande número de intrusões de granitos subalcalinos (2,76 a 2,73 Ga, Complexo Granítico Estrela, Serra do Rabo e similares; 2,57 Ga, Granito Velho Salobo), sucedidos por extensa sedimentação (Formação Águas Claras).

$\mathrm{Na} \mathrm{RX}$, as sequências arqueanas são bordejadas por terrenos paleoproterozoicos dominados por granitoides cálcico-alcalinos da Suíte Parauari, por sequências vulcânicas do Supergrupo Uatumã e granitos tipo-A.

Diferenças entre os três domínios arqueanos estão também refletidas em seus conteúdos metalogenéticos. Os mais importantes depósitos de ouro, cobre, manganês e ferro da PC estão localizados no BC. Na região de Rio Maria, foram encontrados somente pequenos depósitos de ouro e tungstênio. A RX é caracterizada por apresentar depósitos de cassiterita associados a granitos da Suíte Intrusiva Velho Guilherme (Teixeira et al. 2005).

\section{GEOLOGIA DO GRANITO SERINGA O Granito} Seringa está localizado na porção sul-sudeste do estado do Pará, entre os municípios de Ourilândia do Norte e Água Azul do Norte. Apresenta-se como o maior batólito da PC, com forma subcircular. Sua parte central é formada por conjuntos de morros e serras íngremes bem elevadas, chegando à altitude de mais de $700 \mathrm{~m}$. É intrusivo em unidades arqueanas (Fig. 2), seccionando a sudoeste rochas metavulcano-sedimentares, caracterizadas como um conjunto de greenstone-belts pertencentes ao Grupo Tucumã (GT). A sudeste secciona o Trondhjemito Mogno (TM) e a norte o Granodiorito Rio Maria (GRM). Os contatos entre o Granito Seringa e suas encaixantes são em geral bruscos e bem marcados, caracterizando um forte contraste que é nítido nos padrões geomorfológicos. Nas zonas de contatos é comum a presença de enclaves angulosos englobados pelo Granito Seringa. Diques félsicos de orientação preferencial NE-SW e NW-SE cortam tanto as diferentes fácies do Granito Seringa quanto as unidades arqueanas. No limite entre o Granito Seringa e as rochas metavulcânicas, foram registradas ocorrências de granitoides levemente foliados contendo fenocristais de feldspatos alinhados, classificados como quartzo dioritos. Entretanto, tais rochas não foram consideradas como pertencentes ao corpo Seringa.

O Granito Seringa é formado essencialmente por sienogranitos e monzogranitos, de coloração vermelho rosada e granulação que varia de fina a predominantemente grossa. Não mostra sinais de deformação, exceto a presença dos planos de fraturas que as atravessam em todas as direções.

Foram identificados dois grandes conjuntos petrográficos: a) rochas monzograníticas, representadas por bitotita-anfibólio monzogranito grosso (BAMGrG) e anfibólio-bitotita monzogranito grosso (ABMGrG), 

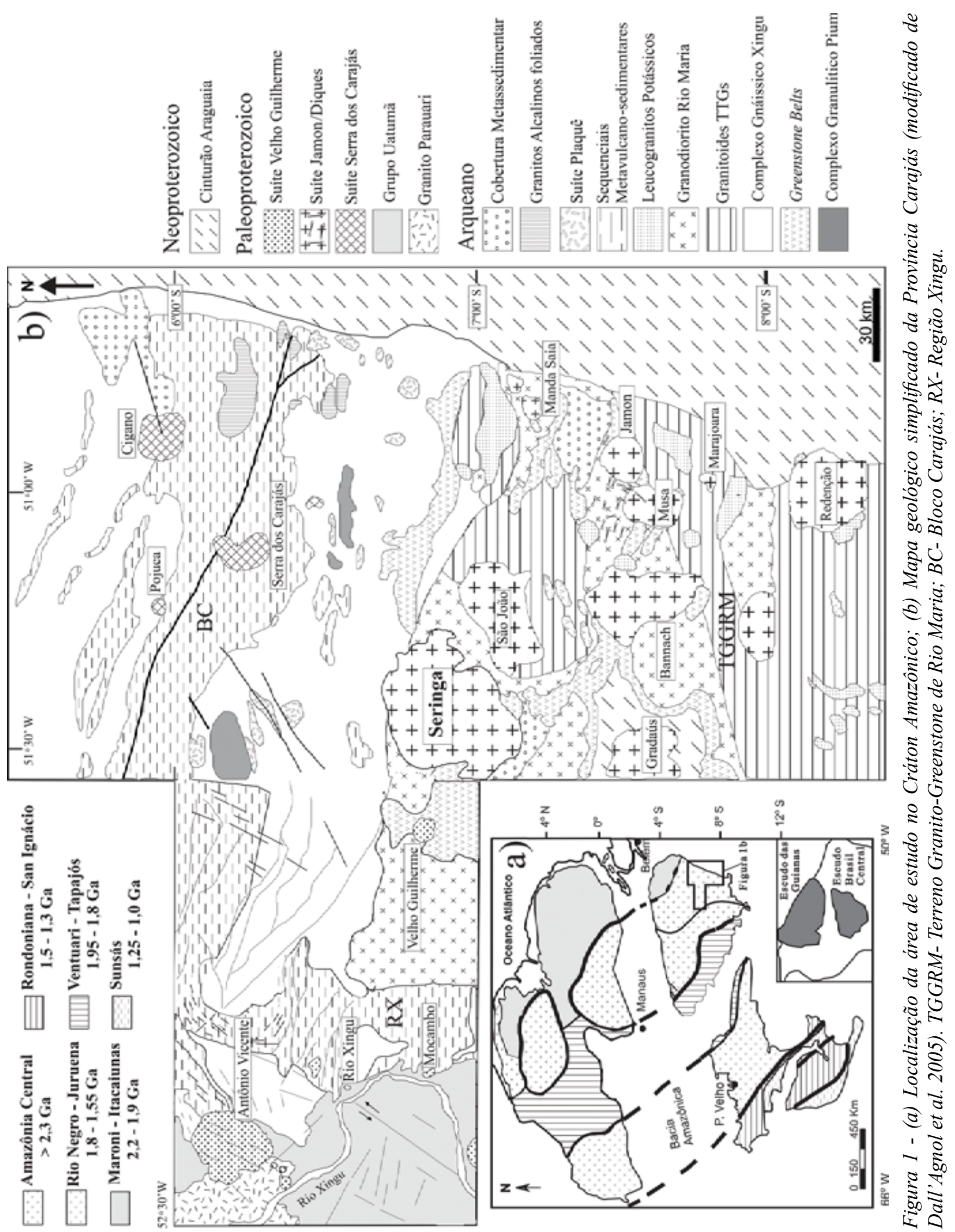


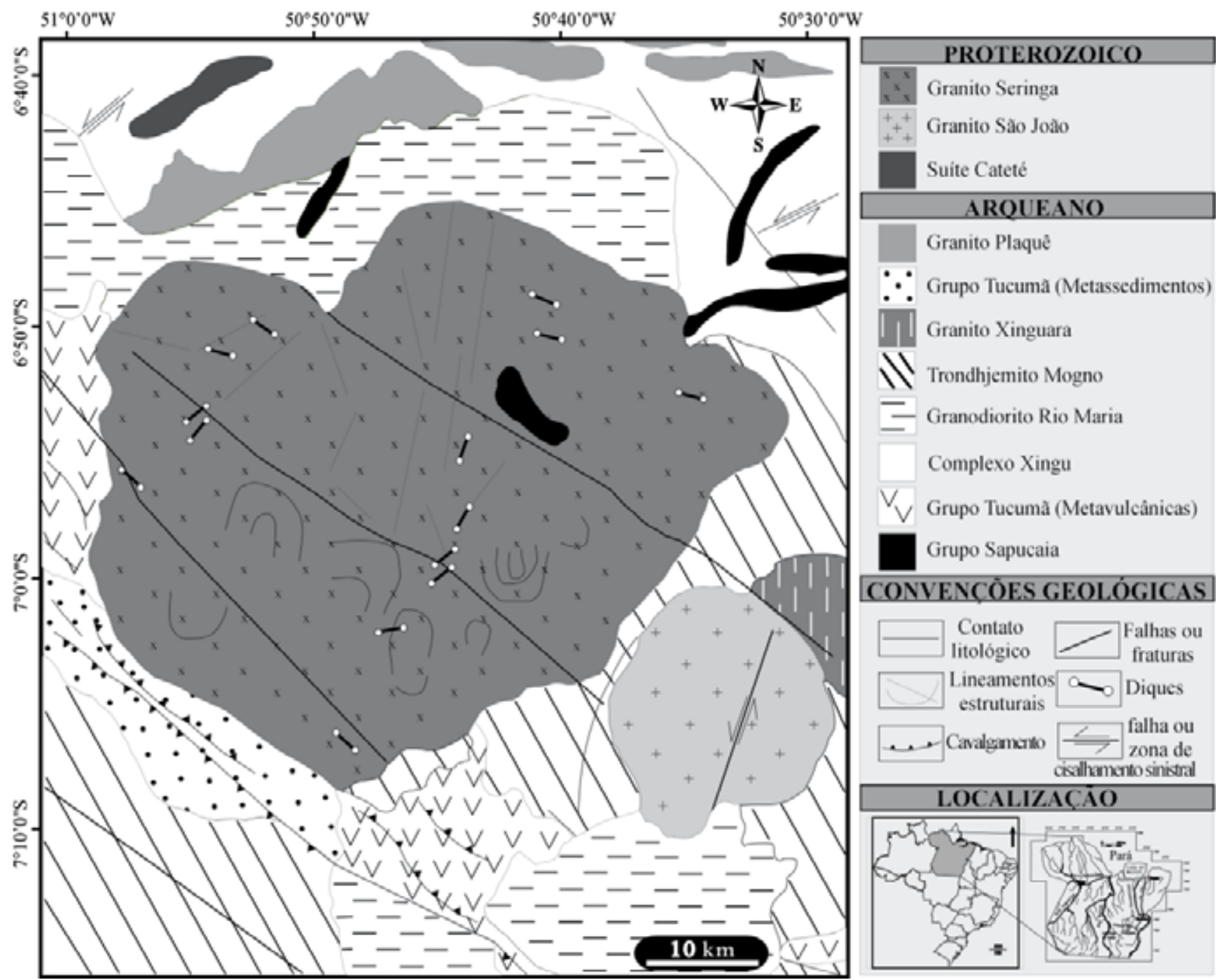

Figura 2 - Mapa Geológico da região de ocorrência do Granito Seringa (Modificado de CPRM 2004).

totalizando quase $60 \%$ da área mapeada; b) rochas sienograníticas, representadas por anfibólio-biotita sienogranito porfirítico (ABSGrP), leucosienogranito heterogranular (LSGrH), leucomicrosienogranito (LMSGr) e anfibólio-biotita sienogranito heterogranular (ABS$\mathrm{GrH})$. Variedades rapakivi ocorrem localmente, por vezes associadas às fácies ABMGrG e ABSGrP.

As rochas monzograníticas (ABMGrG e BAM$\mathrm{GrG}$ ) possuem maior expressão areal e, independente do seu conteúdo modal máfico, ocorrem predominantemente nas porções de relevo mais baixo, sustentando as rochas mais evoluídas. Os contatos entre essas unidades são gradacionais e comumente englobam xenólitos angulosos pertencentes, provavelmente, às rochas metavulcânicas do Grupo Tucumã e, por vezes, autólitos do ABSGrP. A forma angulosa dos xenólitos levemente foliados, o contato brusco entre o Granito Seringa e suas encaixantes, a ausência de orientação planar dos enclaves e de foliações e lineações no corpo granítico, indicam alto contraste de viscosidade e temperatura entre a intrusão granítica e as suas encaixantes (Pitcher \& Berger 1972,
Marre 1982). Tal fato sugere que a colocação do Granito Seringa se deu quando o magma dispunha de uma fração líquida significativa, estando, portanto, em estado físico e térmico distinto daqueles das suas encaixantes, as quais se encontravam, ao que tudo indica, inteiramente cristalizadas e submetidas a menores temperaturas.

Os ABSGrH ocorrem na parte central do corpo, formando, por vezes, anfiteatros e conjuntos de serras alinhadas na direção N-S. Estas rochas não mostram contatos gradacionais com as demais fácies. Diferem das outras variedades petrográficas, visto que o plagioclásio só é observado microscopicamente.

Os ABSGrP ocorrem na porção sudoeste do maciço, mostrando contatos gradacionais com as rochas monzograníticas e abruptos com a fácies LMSGr. São porfiríticos, localmente com texturas rapakivi, sobretudo nas zonas proximais do BAMGrG.

As rochas leucograníticas (LSGrH e LMSGr) representam os termos geoquimicamente mais evoluídos. Predominam nas bordas do maciço formando diques (LMSGr), que constantemente cortam as rochas menos 
evoluídas (ABMGrG e BAMGrG). Os contatos entre as rochas leucograníticas são gradacionais, no entanto, são fortemente abruptos com os ABMGrG.

$\mathrm{Na}$ porção nordeste do Granito Seringa aflora parte do embasamento cristalino, representado por rochas supracrustais metavulcânicas e metassedimentares do Grupo Sapucaia. Este domínio constitui uma área arrasada, onde afloram localmente morrotes e pequenos blocos métricos fortemente alterados e intemperizados do Granito Seringa, o que propiciou o aparecimento do embasamento arqueano.

\section{PETROGRAFIA}

Composição modal e classificação A tabela 1 apresenta as composições modais médias obtidas em quarenta amostras das diferentes fácies petrográficas do Granito Seringa, e a figura 3 a posição das mesmas nos diagramas Q-A-P e Q-A+P-M. A figura 4 apresenta o mapa geológico do Granito Seringa com a identificação de suas diferentes fácies petrográficas.
O Granito Seringa é formado por dois grandes conjuntos de rochas que foram divididos em seis fácies petrográficas: a) rochas monzograníticas, representadas por bitotita-anfibólio monzogranito grosso (BAMGrG) e anfibólio-bitotita monzogranito grosso (ABMGrG); b) rochas sienograníticas, representadas por anfibólio-biotita sienogranito porfirítico (ABSGrP), leucosienogranito heterogranular (LSGrH), leucomicrosienogranito (LMSGr) e anfibólio-biotita sienogranito heterogranular (ABSGrH). As texturas registradas são variáveis, apresentando termos equigranulares de granulação grossa (BAMGrG, ABMGrG e ABSGrP), passando para termos de granulação média (ABSGrH) e finalizando com rochas de granulação fina (LSGrH e LMSGr).

A mineralogia essencial das diferentes fácies do Granito Seringa é representada por quartzo, feldspato potássico e plagioclásio. As fases máficas estão representadas por biotita e anfibólio, às vezes em quantidades expressivas nos BAMGrG, e bem reduzidas nos tipos mais leucocráticos.

Tabela 1- Composições modais médias das diferentes fácies do Granito Seringa.

\begin{tabular}{|c|c|c|c|c|c|c|}
\hline Fácies & ABMGrG & BAMGrG & BSGrP & BSGrH & LSGrH & LMSGr \\
\hline Minerais (\%) & [8] & [7] & {$[8]$} & [7] & [4] & {$[6]$} \\
\hline Quartzo & 28,4 & 27,4 & 35,6 & 40,2 & 41,2 & 36,8 \\
\hline K-Feldspato & 33,8 & 31,1 & 37,7 & 41,6 & 42,6 & 46,3 \\
\hline Plagioclásio & 25,5 & 29,2 & 19,1 & 13,4 & 11,5 & 10,8 \\
\hline Biotita & 2,9 & 5,8 & 2,5 & 3,4 & 2,9 & 2,6 \\
\hline Anfibólio & 7,1 & 3,7 & 2,7 & 0,2 & 0,7 & 1,5 \\
\hline Piroxênio & 0,2 & 0,2 & - & - & - & - \\
\hline Opacos & 1,8 & 1,4 & 0,7 & 0,5 & 0,5 & 1,0 \\
\hline Clorita & 0,5 & 0,3 & 1,2 & 0,3 & 0,3 & 0,6 \\
\hline Fluorita & - & 0,1 & 0,1 & - & - & - \\
\hline Allanita & - & - & - & 0,3 & 0,1 & 0,1 \\
\hline Zircão+Apatita & 0,5 & 0,4 & 0,4 & 0,1 & 0,1 & 0,2 \\
\hline Epidoto+Muscovita & 0,3 & 0,2 & 0,7 & 0,0 & 0,0 & 0,0 \\
\hline Félsicos & 87,8 & 87,7 & 92,3 & 95,2 & 95,2 & 93,8 \\
\hline Máficos & 13,2 & 12,2 & 8,3 & 4,7 & 4,6 & 6,1 \\
\hline $\mathrm{Fk}+\mathrm{Pl}$ & 59,4 & 60,3 & 56,8 & 54,9 & 54,1 & 57,0 \\
\hline$Q+F k$ & 62,3 & 58,6 & 73,2 & 81,8 & 83,7 & 83,0 \\
\hline Anf. + Biot. & 10,0 & 9,5 & 5,1 & 3,6 & 3,6 & 4,1 \\
\hline Biot. + Clorita & 3,5 & 6,2 & 3,6 & 3,7 & 3,3 & 3,3 \\
\hline Anf./Biot. & 2,4 & 0,6 & 1,1 & 0,0 & 0,2 & 0,6 \\
\hline \multicolumn{7}{|l|}{ À $100 \%$} \\
\hline Quartzo & 32,4 & 31,3 & 38,7 & 42,3 & 43,2 & 39,2 \\
\hline K-Feldspato & 38,5 & 35,5 & 41,0 & 43,7 & 44,7 & 49,3 \\
\hline Plagioclásio & 29,1 & 33,2 & 20,3 & 14,0 & 12,1 & 11,5 \\
\hline $\mathrm{Pl} / \mathrm{FK}$ & 0,8 & 0,9 & 0,5 & 0,3 & 0,3 & 0,2 \\
\hline
\end{tabular}

Abreviações: FK - feldspato potássico; Pl - Plagioclásio; Q - Quartzo; Anfibólio; Biot - biotita. [x] representa uma média das análises modais para cada fácies. 
A magnetita geralmente é encontrada em proporções maiores que $1 \%$ nos monzogranitos e alcança conteúdos de até $0,5 \%$ nas rochas mais evoluídas, no entanto, via de regra, é mais abundante que a ilmenita.

A ausência de titanita magmática, mineral comum nos granitos da Suíte Jamon (Dall'Agnol et al. 2005), é uma feição típica nas rochas do Granito Seringa. Característica semelhante é observada nos granitos da Suíte Serra dos Carajás (Javier et al. 1995, Barros et al. 1995).

$\mathrm{O}$ diagrama $\mathrm{Q}-\mathrm{A}+\mathrm{P}-\mathrm{M}$ permite separar rochas com diferentes conteúdos modais de minerais máficos. As rochas monzograníticas, $\mathrm{BAMGrG} \mathrm{eABMGrG,} \mathrm{apre-}$ sentam conteúdos médios de máficos de 13,2 e 12,2\%, respectivamente, e os termos intermediários (ABSGrP) de $8,3 \%$. Nas rochas mais evoluídas (ABSGrH, LSGrH e LMSGr) as concentrações médias de máficos variam de $6,1 \%, 4,7 \%$ e $4,7 \%$, neste mesmo sentido.

Os minerais acessórios mais frequentes são: zircão, magnetita, ilmenita, apatita e allanita. Como produtos de alteração pós-magmático ocorrem clorita, sericita, muscovita, epidoto, fluorita e argilominerais. A composição mineralógica das diferentes fácies permite classificar o Granito Seringa como subsolvus (Tuttle \& Bowen 1958), haja vista a coexistência de FK e plagioclásio como fases primárias independentes.

Os dois conjuntos petrográficos apresentam mineralogia similar, embora as proporções minerais variem muito de um para outro, sobretudo quanto à proporção de minerais máficos. Nas rochas monzograníticas os contatos entre quartzo e anfibólio são retilíneos e regulares. O anfibólio comumente se amolda aos cristais de quartzo e/ou preenche os espaços entre grãos, sugerindo cristalização posterior ou contemporânea ao quartzo. Anfibólio e biotita ocorrem associados nas rochas monzograníticas de modo a sugerir equilíbrio entre eles. Além disso, o anfibólio está muito bem preservado nessas rochas e não há evidências texturais claras de reações peritéticas entre ele e o líquido para gerar biotita, titanita e quartzo, como frequentemente é observado nos granitos da Suíte Jamon (Dall'Agnol et al. 1999a, Oliveira et al. 2002, Almeida 2005). O anfibólio presente nas rochas monzograníticas do Granito Seringa parece ser mais tardio em termos de cristalização que os anfibólios encontrados nos granitos da Suíte Jamon.

\section{ASPECTOS TEXTURAIS}

Rochas monzograníticas (BAMGrG e ABMGrG) As rochas monzograníticas são isotrópicas, de coloração rosa avermelhada e textura equigranular grossa, apresentando, por vezes, textura rapakivi. Ao microscópio mostram textura granular hipidiomórfica grossa.

O quartzo apresenta-se em três tipos morfológicos distintos: a) $Q t z_{1}$ ocorre como cristais euédricos a anédricos, com dimensões por vezes maiores que $1 \mathrm{~cm}$, formando contatos retilíneos e regulares com o feldspato potássico e anfibólio. Localmente mostra extinção ondulante e inclusões de minerais acessórios e plagioclásio; b) $Q t z_{2}$ forma cristais finos a médios, angulosos

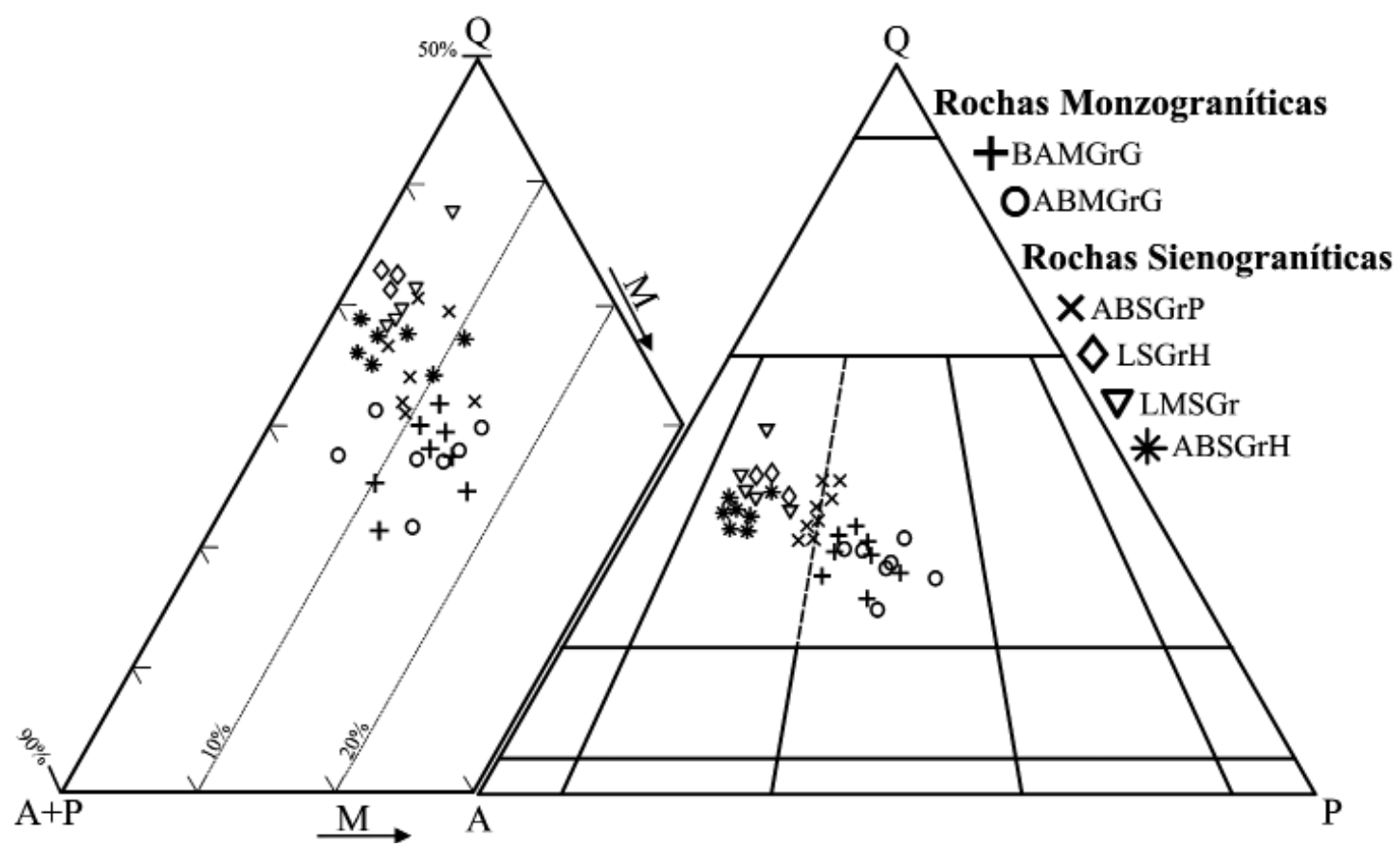

Figura 3 - Diagramas modais $Q-A-P$ (Le Maitre 2002) e $Q-(A+P)-M$ para as fácies do Granito Seringa. A - Feldspato alcalino; $Q$ - quartzo; $P$ - plagioclásio; $M$ - máficos; BAMGrG -biotitaanfibólio monzogranito grosso; $A B M G r G$ - anfibólio-biotita monzogranito grosso; ABSGrP - anfibólio-biotita sienogranito porfirítico; LSGrH - leucosienogranito heterogranular; LMSGr - leucomicrosienogranito; ABSGrH - anfibólio-biotita sienogranito heterogranular. 
a subarredondados, associados aos cristais de feldspato potássico pertítico; c) $Q t z_{3}$ apresenta formas vermiculares ou em gotas, constituindo intercrescimentos granofíricos com o feldspato potássico.

O feldspato potássico (FK) forma cristais grossos a médios, anédricos a subédricos. É pertítico, com lamelas sódicas de aspecto variável, desde filmes ondulantes até veios e manchas irregulares. No contato entre cristais pertíticos é comum o desenvolvimento de bordas albíticas ou de incipientes coroas trocadas de albita intergranular. Pseudocoroas de $Q t z{ }_{2}$ ao redor do núcleo de cristais de FK zonado são comumente observadas. Essa feição reliquiar foi interpretada por Dall'Agnol (1980) como resultado de reabsorção parcial, com cristalização do FK em duas etapas. As inclusões de FK teriam se formado precocemente, antecedendo plagioclásio e quartzo enquanto os demais cristais de FK se formariam após o início da cristalização do plagioclásio e mais ou menos simultaneamente com a do quartzo. Sinais de alteração estão evidenciados pela argilização dos cristais de FK, cujo grau aumenta em direção aos ABSGrH.

O plagioclásio $(\mathrm{Pl})$ apresenta-se como cristais subédricos, médios a grossos $(3$ a $10 \mathrm{~mm})$. Seus contatos são regulares e por vezes interpenetrantes com o quartzo e a biotita, porém irregulares com o FK, que normalmente circunda o plagioclásio. Os cristais mostram zoneamento normal com teores de anortita entre $\mathrm{An}_{32}$ e $\mathrm{An}_{25}$, dentro, portanto, da faixa composicional andesina-oligoclásio. Foram obtidos valores de anortita um pouco mais baixos nas bordas de cristais zonados $\left(\mathrm{An}_{12}\right)$. Comumente mostram-se alterados para albita, sericita, muscovita e epidoto.

O anfibólio desenvolve cristais grossos a finos, anédricos a subédricos, englobam frequentes inclusões de zircão, apatita e opacos, mostram pleocroísmo moderado, variando de verde escuro a verde acastanhado. Descreve contatos retilíneos e regulares com os cristais de quartzo, onde comumente amolda-se e preenche os espaços do mesmo, sugerindo que sua cristalização foi posterior ou contemporânea ao quartzo.

A biotita mostra-se como lamelas médias a finas, anédricas a subédricas, exibindo pleocroísmo fraco a moderado, variando de creme amarelado a marrom escuro, eventualmente com tons avermelhados, provavelmente em função da oxidação. Raramente altera-se para clorita.

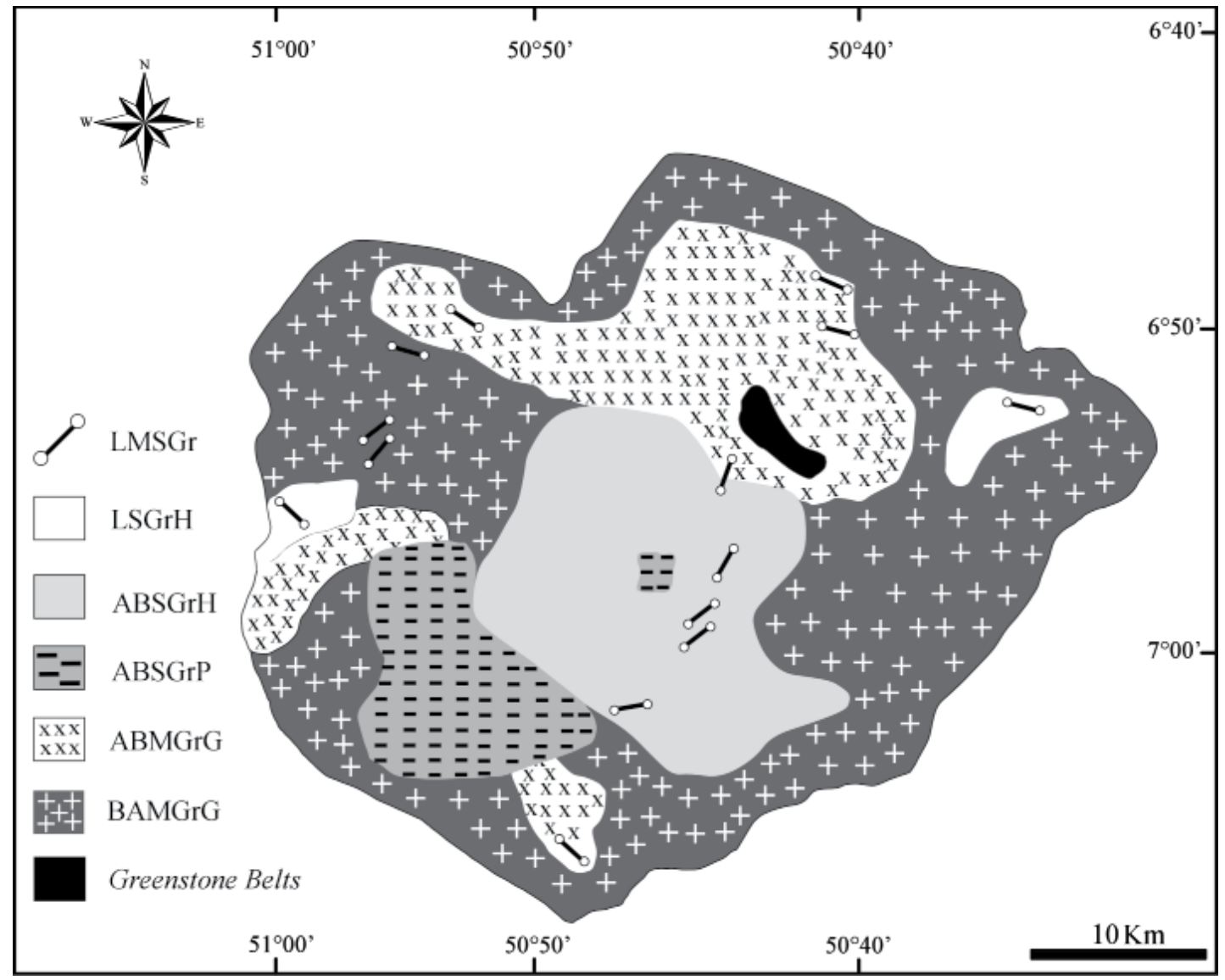

Figura 4 - Mapa geológico do Granito Seringa, mostrando a distribuição espacial das suas diferentes fácies. BAMGrG - biotita-anfibólio monzogranito grosso; ABMGrG- anfibóliobiotita monzogranito grosso; ABSGrP - anfibólio-biotita sienogranito porfiritico; LSGrH leucosienogranito heterogranular; $L M S r G$ - leucomicrosienogranito; ABSGrH - anfibóliobiotita sienogranito heterogranular. 
Dentre os minerais acessórios primários figuram zircão, apatita, allanita e opacos, estes últimos representados por magnetita e ilmenita. Zircão e apatita ocorrem como inclusões, principalmente no anfibólio.

Rochas sienograníticas (ABSGP, ABSGH, LSGH, LMSG) Embora agrupadas num só conjunto, as rochas sienograníticas mostram diferenças, sobretudo no aspecto textural. A fácies ABSGrP é marcada por sua coloração rosa esbranquiçada, localmente acinzentada, com fenocristais bem desenvolvidos. Suas características mineralógicas, composição do plagioclásio e morfologia do FK são semelhantes às das rochas monzograníticas. Apresenta textura porfirítica, caracterizada por fenocristais de FK e plagioclásio, imersos numa matriz fanerítica, formada por cristais anédricos a subédricos de FK, plagioclásio, quartzo e proporções variadas de máficos, totalizando cerca de $60 \%$ da rocha. Os cristais de quartzo mostram muitas vezes bordas com padrões serrilhados, sugerindo corrosão. Agregados de plagioclásio e biotita cloritizada são comuns.

A fácies ABSGrH é caracterizada por sua coloração intensamente avermelhada e granulação média. Macroscopicamente é formada por feldspato potássico, quartzo e minerais máficos. Microscopicamente o plagioclásio chega a teores de até $11 \%$. Biotita e anfibólio ocorrem como fases varietais com dominância da biotita, chegando a ser, por vezes, fase exclusiva. Os intercrescimentos granofíricos podem atingir até $40 \%$ da rocha. A biotita altera para clorita, óxido de ferro, epidoto e opacos, acompanhando o sentido preferencial das direções de clivagem. Engloba em seu interior pequenas inclusões de quartzo, apatita, minerais opacos e zircão.

As fácies LSGrH e LMSGr mostram grandes semelhanças texturais e mineralógicas, exibem coloração rosada, aspecto maciço e textura granular hipidiomórfica. Diferem quanto à granulação e forma de colocação, onde os LMSGr formam diques que seccionam praticamente todas as demais fácies. A biotita é mais frequente que o anfibólio, que por sua vez mostra-se como mineral reliquiar, de granulação fina, disperso entre os minerais essenciais. A fácies LSGrH ocorre muito localmente, sempre associada com os BAMGrG e ABMGrG. Mostra grandes semelhanças com estas, principalmente no que diz respeito aos cristais de quartzo e feldspatos. Entretanto, difere das mesmas quanto ao conteúdo de máficos e quantidade de intercrescimentos granofíricos, que são muito abundantes nos LSGrH e LMSGr. O plagioclásio possui composição ligeiramente mais sódica $\left(A n_{18}\right)$ e as alterações do FK são mais marcantes que nas fácies precedentes. A formação de albita em tabuleiro de xadrez e albita intergranular com textura em coroas trocadas é marcante nessas rochas.

GEOQUÍMICA As análises químicas foram realizadas na ACME-Analytical Laboratories LTDA. Os elementos maiores e menores $\left(\mathrm{SiO}_{2}, \mathrm{TiO}_{2}, \mathrm{Al}_{2} \mathrm{O}_{3}, \mathrm{Fe}_{2} \mathrm{O}_{3}\right.$, $\mathrm{MgO}, \mathrm{CaO}, \mathrm{MnO}, \mathrm{Na}_{2} \mathrm{O}, \mathrm{K}_{2} \mathrm{O}, \mathrm{P}_{2} \mathrm{O}_{5}$ ) foram analisados por ICP-ES (Inductively Coupled Plasma-Emission
Spectrometry) e os traços ( $\mathrm{Rb}, \mathrm{Sr}, \mathrm{Ba}, \mathrm{Ga}, \mathrm{Y}, \mathrm{Zr}, \mathrm{Nb}, \mathrm{U}$, $\mathrm{Th}, \mathrm{Cr}, \mathrm{Ni}, \mathrm{V})$, incluindo os Terras Raras ( $\mathrm{La}, \mathrm{Ce}, \mathrm{Nd}$, $\mathrm{Sm}, \mathrm{Eu}, \mathrm{Gd}, \mathrm{Dy}, \mathrm{Er}, \mathrm{Yb}$ e Lu) por ICP-MS (Inductively Coupled Plasma-Mass Spectrometry).

Elementos maiores A caracterização geoquímica do Granito Seringa envolveu 17 amostras (Tab. 2), distribuídas da seguinte forma: BAMGrG (5), ABMGrG (2), ABSGrP (3), ABSGrH (3), LSGrH (2) e LMSGr (2). Os conteúdos de $\mathrm{SiO}_{2}$ variam de 69,7 a 77,7\%, individualizando claramente dois conjuntos. O primeiro, formado pelas rochas monzograníticas (BAMGrG e ABMGrG), com valores de $\mathrm{SiO}_{2}$ mais baixos (média de 70\%), e o segundo pelas rochas sienograníticas (ABSGrP, ABS$\mathrm{GrH}$, LSGrH e LMSGr), cujos valores de $\mathrm{SiO}_{2}$ variam de 74,4 a 77,7\%. Os dados obtidos não mostram continuidade composicional, expondo um nítido "gap" entre os dois conjuntos petrográficos. Isso é mais evidente nos diagramas de variação de Harker (Fig. 5).

As rochas monzograníticas apresentam teores mais elevados de $\mathrm{TiO}_{2}, \mathrm{Fe}_{2} \mathrm{O}_{3} \mathrm{t}, \mathrm{MgO}, \mathrm{CaO}$ e $\mathrm{P}_{2} \mathrm{O}_{5}$, e mais reduzidos de $\mathrm{K}_{2} \mathrm{O}$, distinguindo-se das rochas sienograníticas. Essas diferenças composicionais, juntamente com os conteúdos mais elevados de minerais máficos das primeiras, sugerem processo de cristalização fracionada a partir de um magma parental e formando líquidos que vão se injetando em vários pulsos.

Com o aumento de sílica, no sentido das rochas monzograníticas para as sienograníticas, os teores de $\mathrm{TiO}_{2}, \mathrm{Fe}_{2} \mathrm{O}_{3} \mathrm{t}, \mathrm{MgO}, \mathrm{CaO}$ e $\mathrm{P}_{2} \mathrm{O}_{5}$ tendem a diminuir, ao passo que aumentam os teores de $\mathrm{K}_{2} \mathrm{O}$. Isso é coerente com as observações petrográficas, as quais mostram que as razões $\mathrm{Pl} / \mathrm{FK}$ e Anf/Biot (Tab. 1), juntamente com os conteúdos modais de minerais ferromagnesianos, exibem valores decrescentes nesse mesmo sentido.

As rochas do Granito Seringa são ricas em álcalis $\left(\mathrm{K}_{2} \mathrm{O}+\mathrm{Na}_{2} \mathrm{O} \sim 7,5 \%\right)$, com teores de $\mathrm{K}_{2} \mathrm{O}$ aproximadamente o dobro de $\mathrm{Na}_{2} \mathrm{O}$, sobretudo nas rochas sienograníticas, refletindo a dominância do feldspato potássico sobre o plagioclásio. Além disso, mostram razões $\mathrm{K}_{2} \mathrm{O}$ / $\mathrm{Na}_{2} \mathrm{O}$ entre 1 e 2 (Fig. 6A), caracterizando as diferentes fácies como relativamente enriquecidas em $\mathrm{K}_{2} \mathrm{O}$.

Embora os elementos maiores mostrem uma correlação linear negativa com o aumento de sílica, com exceção do $\mathrm{K}_{2} \mathrm{O}$, as rochas sienograníticas (ABSGrH e ABSGrP) mostram trends distintos especialmente para $\mathrm{TiO}_{2}, \mathrm{MgO}$ e CaO, em comparação com as rochas leucograníticas (LSGrH e LMSGr).

A figura 6B mostra que o Granito Seringa possui sempre altas razões de $\mathrm{FeOt} /(\mathrm{FeOt}+\mathrm{MgO})(0,86$ a 0,97), os quais tendem a aumentar nas variedades mais ricas em sílica, refletindo a diminuição mais acentuada de $\mathrm{MgO}$ em relação a $\mathrm{FeOt}$ nessas rochas. Pode ser classificado como do tipo rico em ferro (Frost et al. 2001), exibindo comportamento semelhante ao dos granitos tipo A.

O Granito Seringa mostra caráter metaluminoso a levemente peraluminoso (Fig. 6C) revelado no diagrama ANK versus ACNK (Shand 1951), e é corroborado pelo diagrama (Fig. 6D) $\mathrm{Fe}+\mathrm{Mg}+\mathrm{Ti}$ versus $\mathrm{Al}-(\mathrm{K}+\mathrm{Na}+2 \mathrm{Ca})$ de Debon et al. (1988). Além disso, 


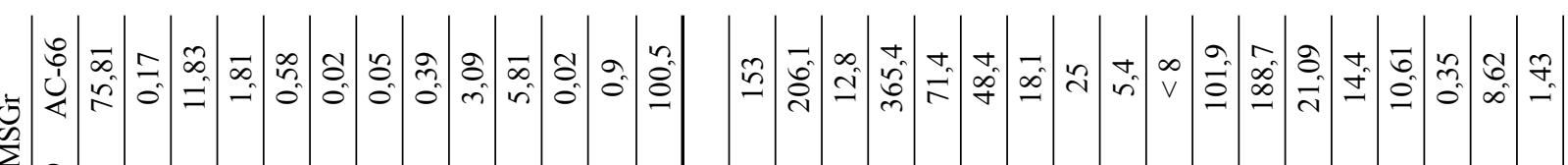
$\sum^{n}$

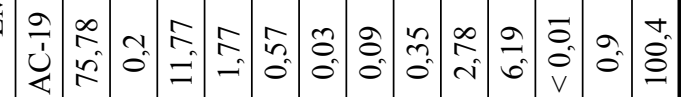

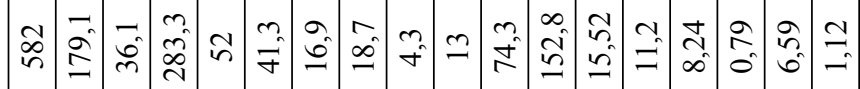

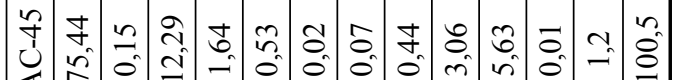
震

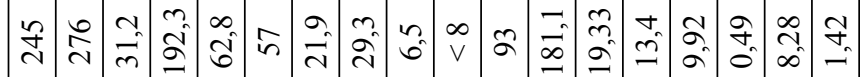

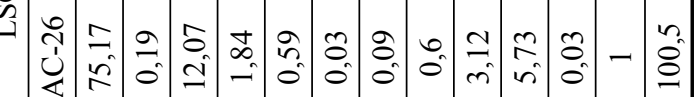

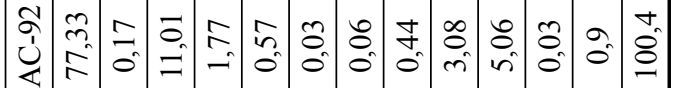

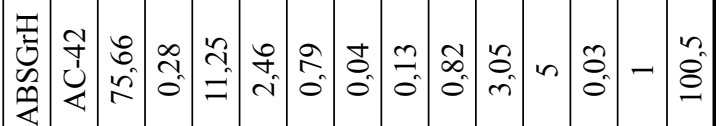

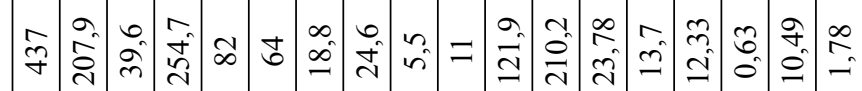

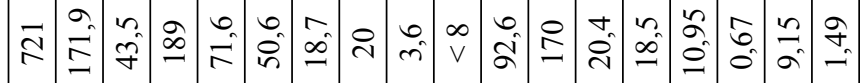

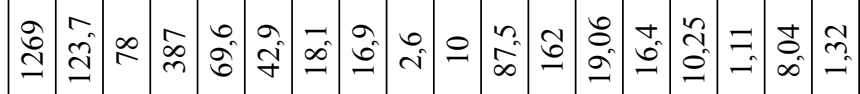

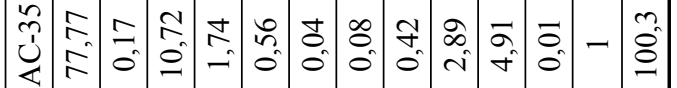

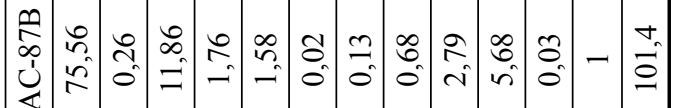

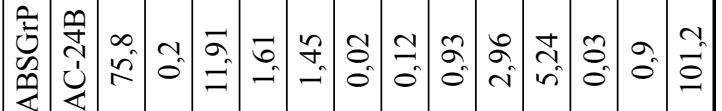

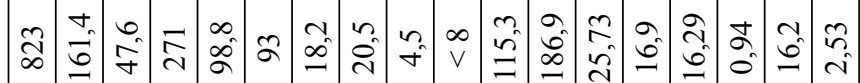

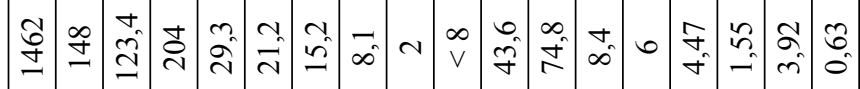

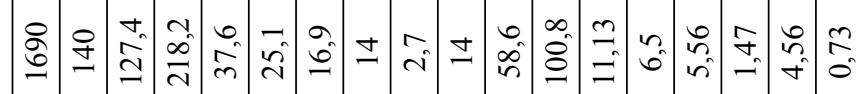

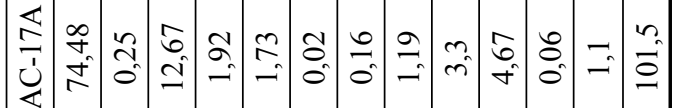

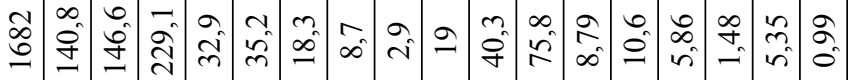

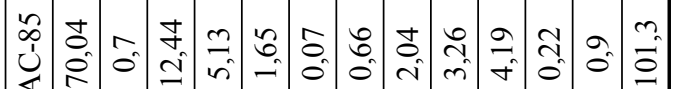

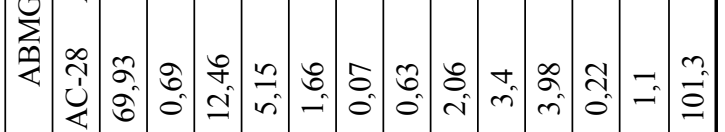

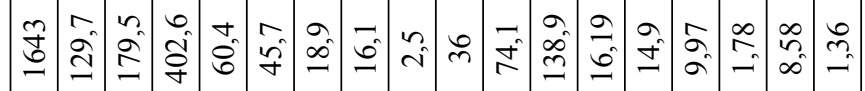

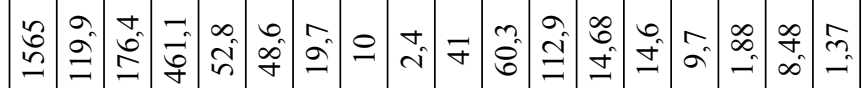

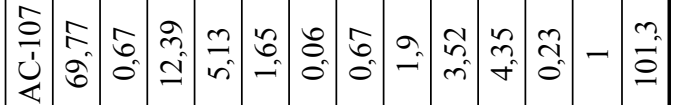

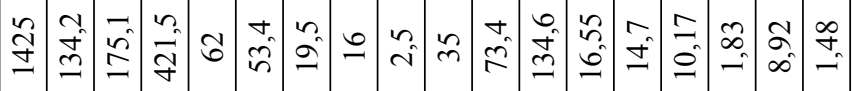

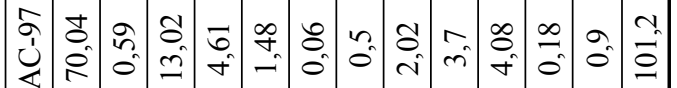

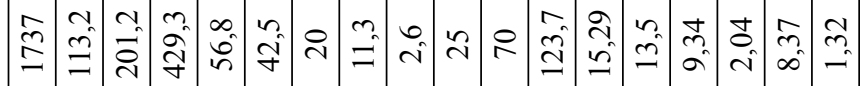

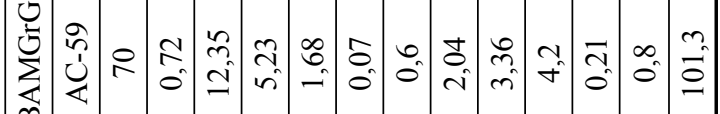

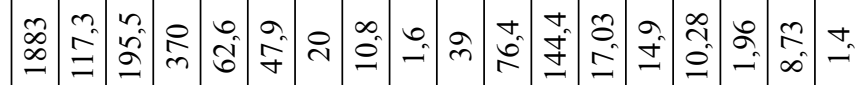

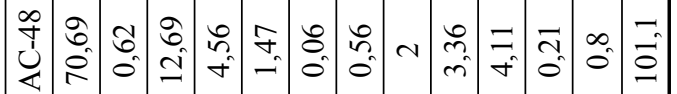

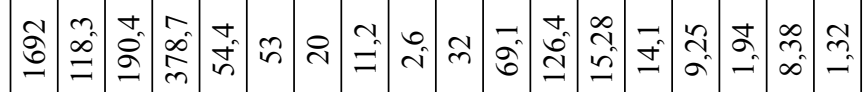

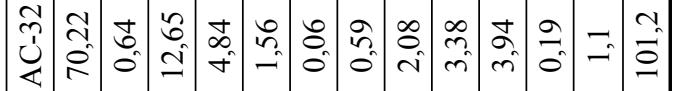

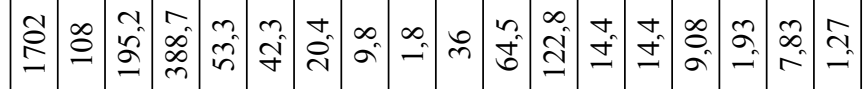




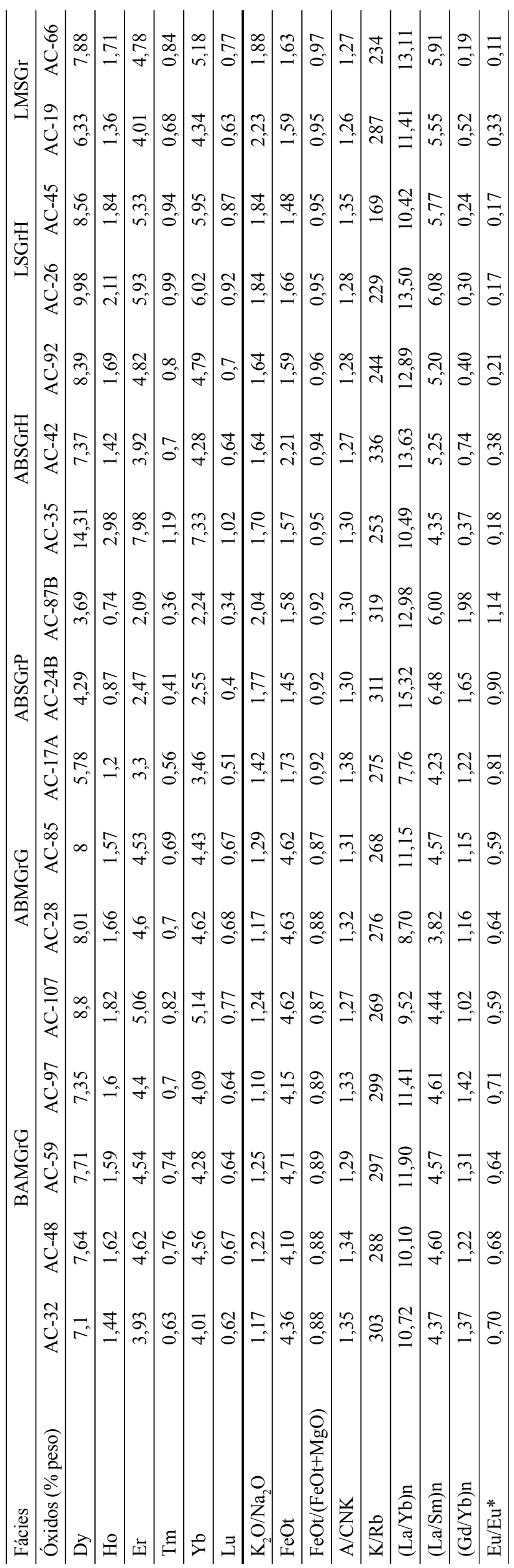

neste último diagrama, percebe-se que, com a diminuição dos minerais máficos, as rochas passam de metaluminosas (campo IV- hornblenda + biotita) para peraluminosas (campo III- biotita), e que as rochas sienograníticas seriam classificadas geoquimicamente como leucogranitos.

\section{Elementos traços}

COMPORTAMENTO DE Rb, Sr E Ba O conteúdo dos elementos traços em séries magmáticas varia de acordo com a diferenciação magmática e pode auxiliar na compreensão dos processos envolvidos na mesma. Biotita e feldspatos são minerais importantes na diferenciação magmática de rochas silicáticas, pois são bons receptores de $\mathrm{Rb}$ (Wedepohl 1970). As variações dos teores de $\mathrm{Rb}$ (Fig. 7A) são expressivas e aumentam dos ABMGrG e BAMGrG para os ABSGrP e ABSGrH, até valores mais elevados nas rochas leucograníticas (LSGrH e LMSGr).

$\mathrm{Sr}$ e Ba (Figs. 7B, C) convergem em sentido contrário ao $\mathrm{Rb}$, mostrando correlação negativa com o aumento da sílica e acentuada diminuição dos ABSGrP e ABSGrH para as rochas leucograníticas. Essa tendência mostra que, em líquidos silicáticos, o $\mathrm{Sr}$ se concentra fundamentalmente em plagioclásios de composições intermediárias (andesina a oligoclásio cálcico) e, subordinadamente, no feldspato potássico. A cristalização do plagioclásio empobreceria o líquido em $\mathrm{Sr}$ e a do feldspato potássico, não muito tardia, contribuiria para acentuar essa tendência (cf. Wedepohl 1970).

$\mathrm{O} \mathrm{Ba}$ acompanha mais facilmente o feldspato potássico e as micas, mas teores significativos podem ocorrer em plagioclásios intermediários. No Granito Seringa, a diminuição dos teores de $\mathrm{Ba}$ deve estar ligada, provavelmente, ao fracionamento de feldspato potássico e biotita.

COMPORTAMENTO DE Zr, Y E Nb No Granito Seringa, as rochas monzograníticas apresentam os maiores conteúdos de $\mathrm{Zr}$, com valores médios em torno de $400 \mathrm{ppm}$. As rochas sienograníticas e leucograníticas mostram conteúdos de $\mathrm{Zr} \leq 300 \mathrm{ppm}$, com exceção das amostras AC-42 e AC-66 com 387 ppm e 365 ppm, respectivamente (Tab. 2). Y e Nb apresentam comportamento muito irregular, formando trends sub-horizontalizados $(\mathrm{Y})$ a difusos $(\mathrm{Nb})$, partindo das rochas monzograníticas para as sienograníticas. Segundo Taylor (1965) o Y pode estar contido nos anfibólios e em minerais acessórios cálcicos. Como Y e Nb são compatíveis com hornblenda e zircão, eles poderiam estar presentes em grande parte nesses minerais, muito embora alguns leucogranitos apresentem valores de $\mathrm{Y}$ iguais ou superiores aos dos BAMGrG e ABMGrG.

Embora existam diversidades petrográficas nas rochas estudadas, os dados químicos não indicam estarem elas relacionadas a um trend de diferenciação magmática único, ainda que se possam caracterizar termos menos e mais evoluídos. O gap composicional, existente entre as rochas monzograníticas e sienograníticas, 


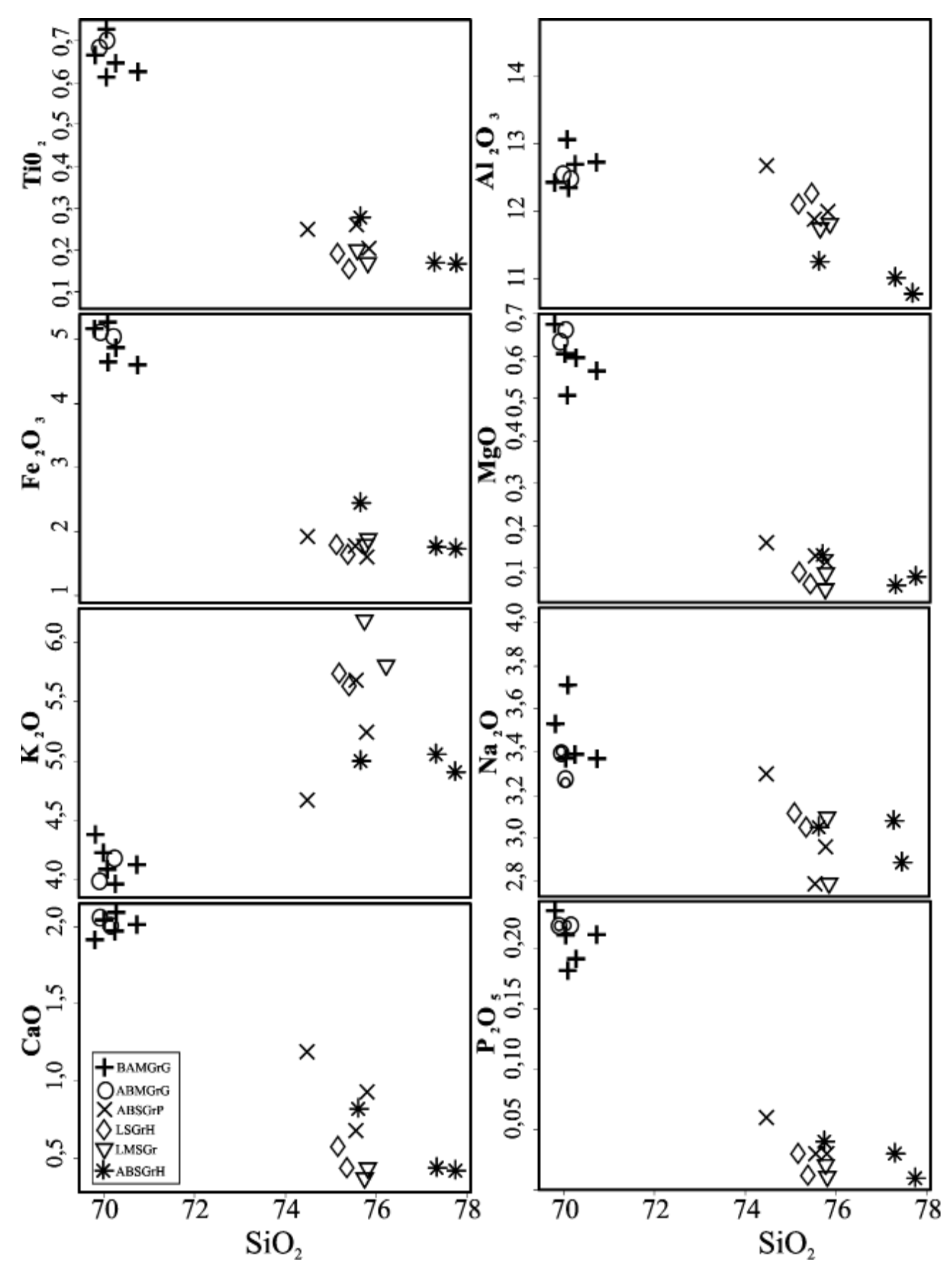

Figura 5 - Diagramas de Harker para os elementos maiores e menores (\% em peso) das diversas fácies do Granito Seringa.

corrobora essa hipótese. Por outro lado, os diques de microgranitos (LMSGr) podem ser o registro de pulsações mais tardias do magma granítico, algumas com composição levemente diferente daquela que gerou o corpo intrusivo principal.

COMPORTAMENTO DOS ELEMENTOS TERRAS RARAS Os dados analíticos dos elementos terras raras (ETR) foram normalizados pelos valores condríticos de Nakamura (1974). De modo geral, o Granito Seringa mostra padrões de ETR (Fig. 8) análogos aos demais granitos anorogênicos que formam a Suíte Serra dos Carajás (Barros et al. 1995, Fig. 9), com elevados teores de elementos terras raras leves (ETRL), padrão sub-horizontalizado dos elementos terras raras pesados (ETRP) e moderadas anomalias negativas de európio (Eu) para os monzogranitos e acentuadas para os sienogranitos, com exceção da fácies $\mathrm{ABSGrP}$ que não apresenta anomalia de Eu. O comportamento geral dos ETR das diferentes fácies do Granito Seringa resulta num padrão levemente inclinado no sentido dos ETRP, indicando que houve um moderado fracionamento dos mesmos.

A fácies LSGrH apresenta maior conteúdo total de ETR (420 ppm) e a mais pronunciada anomalia negativa de $\mathrm{Eu}\left(\mathrm{Eu} / \mathrm{Eu}^{*}=0,17\right)$. O elevado conteúdo 
modal de allanita, zircão e apatita (Tab. 1) pode explicar em parte esse enriquecimento em ETR, e sua anomalia negativa de $\mathrm{Eu}$, mais acentuada (Fig. 8), sugere que o líquido gerador dessa fácies sofreu um fracionamento expressivo dos feldspatos. As pequenas anomalias negativas de Eu observadas nas rochas monzograníticas poderiam sugerir que as rochas sienograníticas derivaram da primeira por simples cristalização fracionada dos feldspatos.

Ambiente tectônico e tipologia Uma das classificações mais difundidas de rochas granitoides baseia-se na fonte de seus magmas. Chappel \& White (1974) introduziram o conceito de granitos do tipo I e S, para rochas derivadas de fontes ígneas e metapelíticas, respectivamente. No final da década de 70, Loiselle \& Wones (1979) introduziram a terminologia de granitos tipo A para designar granitos anorogênicos de natureza alcalina e supostamente anidros. Os granitos do tipo A apresentam valores elevados de $\mathrm{SiO}_{2}(>70 \%), \mathrm{Fe} / \mathrm{Mg}, \mathrm{Zr}$, $\mathrm{Nb}, \mathrm{Y}, \mathrm{Ga}$, e ETR, com exceção do Eu, e baixos $\mathrm{CaO}$, $\mathrm{MgO}, \mathrm{Ba}$ e Sr (Whalen et al. 1987). Finalmente, White
(1979) propôs a terminologia de granitos tipo M para caracterizar granitos de origem mantélica. A gênese de granitos tipo A foi inicialmente explicada a partir de duas hipóteses principais: cristalização fracionada de magmas basálticos alcalinos (Eby 1992) e fusão parcial de crosta granulítica residual (Collins et al. 1982).

As características gerais do Granito Seringa são, à primeira vista, compatíveis tanto com granitos tipo I quanto com granitos tipo A. Dentre os primeiros, destacam-se a presença de anfibólio e biotita, sua tendência subalcalina e seu caráter metaluminoso a fracamente peraluminoso. Além disso, seu caráter oxidado, revelado pelos valores moderados de suscetibilidade magnética $\left(1,3153 \times 10^{-3}\right.$ a $\left.20,0353 \times 10^{-3}\right)$, conteúdos modais de opacos superiores a $0,1 \%$, presença de magnetita em todas as fácies, bem como razões $\mathrm{Fe}_{2} \mathrm{O}_{3} / \mathrm{FeO}$ (rocha total) próximas da unidade (Paiva Jr. 2009), permitem classificá-lo como granito da série, a magnetita, de acordo com a definição de (Ishihara 1981).

Por outro lado, seus altos teores de $\mathrm{SiO}_{2}(69,7$ a $77,7 \%$.), $\mathrm{K}_{2} \mathrm{O}+\mathrm{Na}_{2} \mathrm{O}(8,04 \%), \mathrm{Zr}, \mathrm{Nb}, \mathrm{Y}$ e Ga e suas altas razões $\mathrm{K}_{2} \mathrm{O} / \mathrm{Na}_{2} \mathrm{O}$ e $\mathrm{Ga} / \mathrm{Al}$, o aproximam mais do
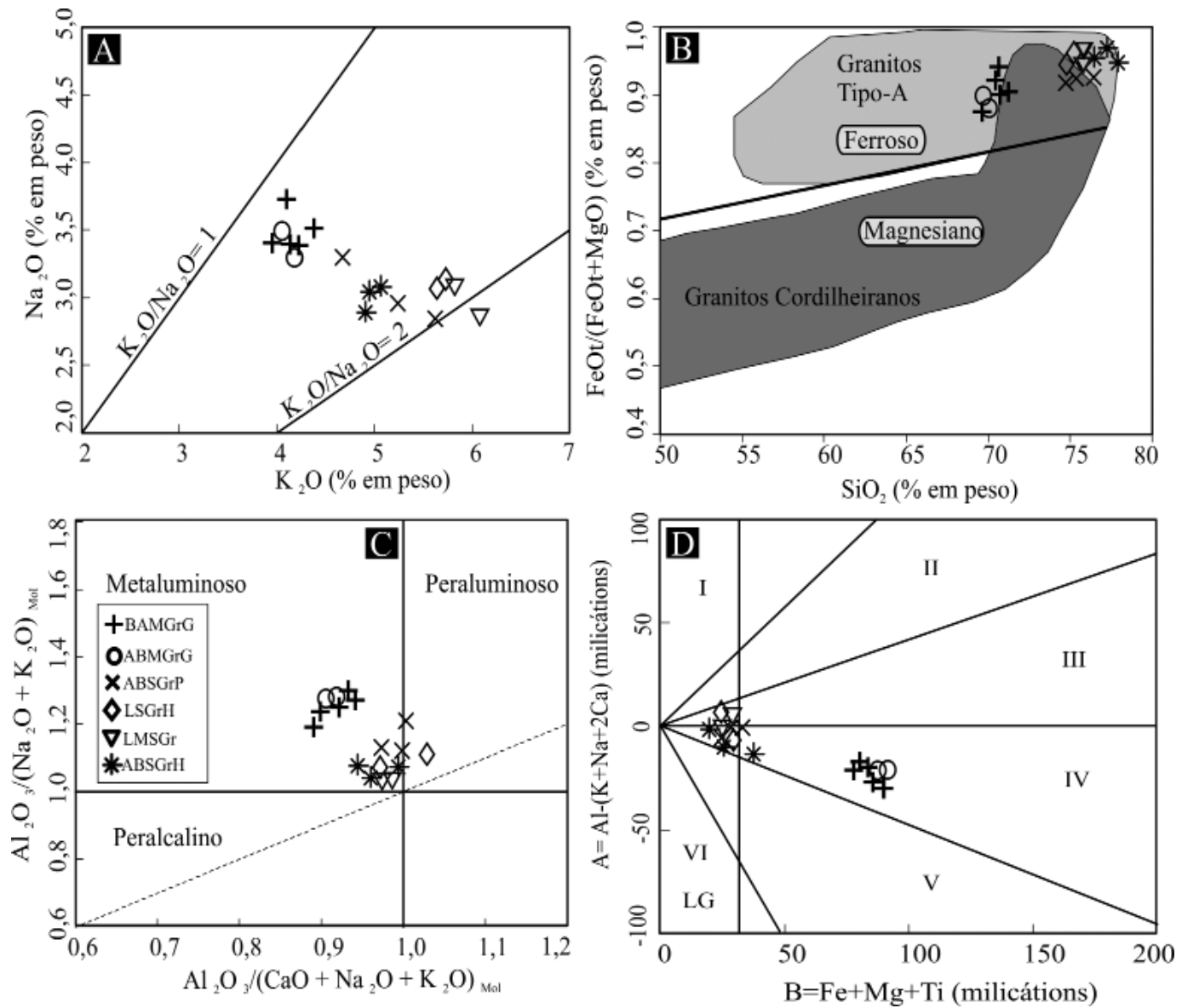

Figura 6 - Diagramas geoquímicos para as rochas do Granito Seringa. A) diagrama $\mathrm{K}_{2} \mathrm{O} \times \mathrm{Na}_{2} \mathrm{O}$; B) diagrama $\mathrm{SiO}_{2} \times \mathrm{FeOt} /(\mathrm{FeOt}+\mathrm{MgO})$ de Frost et al. (2001); C) diagrama ( $\mathrm{ACNK} \times \mathrm{ANK}) \mathrm{Al}_{2} \mathrm{O}_{3} /\left(\mathrm{CaO}+\mathrm{Na}_{2} \mathrm{O}+\mathrm{K}_{2} \mathrm{O}\right) \mathrm{mol} \times \mathrm{Al}_{2} \mathrm{O}_{3} /\left(\mathrm{Na}_{2} \mathrm{O}+\mathrm{K}_{2} \mathrm{O}\right) \mathrm{mol}$ de Shand (1951); D) diagrama B x A (Debon et al. 1988); Campos I - muscovita > biotita, II - biotita > muscovita, III - rochas apenas com biotita, IV - rochas com biotita, anfibólio \pm piroxênio, $V$ - rochas com clinopiroxênio, VI - rochas igneas excepcionais e LG - leucogranitoides. 

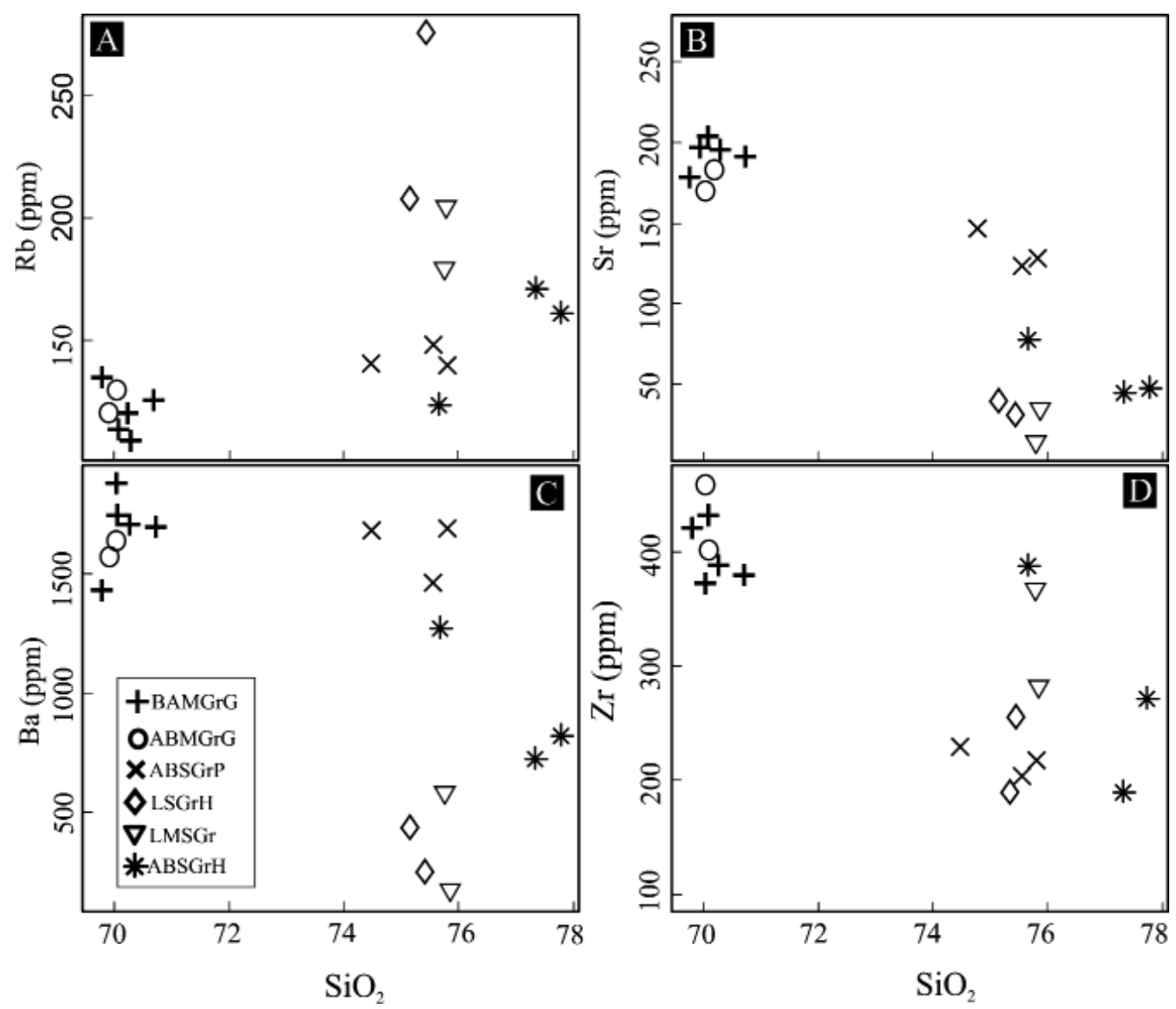

Figura 7 - Diagramas de Harker para os elementos traço das amostras do Granito Seringa. Siglas conforme figura 6.

tipo A. Entretanto, seus conteúdos de $\mathrm{TiO}_{2}, \mathrm{CaO}, \mathrm{MgO}$, $\mathrm{Sr}$ e Ba são relativamente altos, quando comparados com os granitos tipo A do cinturão australiano (Whalen et al. 1987, King et al. 1997).

Whalen et al. (1987) recomendam o uso da razão $\mathrm{Ga} / \mathrm{Al}$ como discriminante de granitos tipo A. Nos diagramas $\mathrm{Zr} \times \mathrm{Ga} / \mathrm{Al}$ (Fig. 10A) e $\left(\mathrm{K}_{2} \mathrm{O}+\mathrm{Na}_{2} \mathrm{O} / \mathrm{CaO}\right.$ $\mathrm{x} \mathrm{Zr}+\mathrm{Nb}+\mathrm{Ce}+\mathrm{Y}$ ) (Fig. 10B) verificam-se que o Granito Seringa apresenta afinidade com os granitos tipo A. Além disso, no diagrama Nb-Y de Pearce et al. (1984, Fig. 10C), o Granito Seringa mostra afinidades geoquímicas com granitos intraplacas, o que é característico de granitos tipo A (Whalen et al. 1987).

No diagrama $\mathrm{FeOt} /(\mathrm{FeOt}+\mathrm{MgO})$ versus $\mathrm{SiO}_{2}$ (Fig. 6C), proposto por Frost et al. (2001) para classificar granitoides com base nas condições de oxidação, as amostras do Granito Seringa incidem no campo dos granitos ricos em ferro, semelhantes aos granitos tipo A. Segundo Eby (1992), granitos tipo A podem ser divididos geoquimicamente em dois grupos. $\mathrm{O}$ primeiro $\left(\mathrm{A}_{1}\right)$ representa os diferenciados de magmas derivados de uma fonte semelhante a basaltos de ilhas oceânicas (OIB), mas colocados em ambiente de rift continental ou de magmatismo intraplacas (hot spot). O segundo $\left(\mathrm{A}_{2}\right)$ representaria magmas derivados parcial ou totalmente de fontes da crosta continental ou magmatismo de arco de ilha (IAB). Segundo essas características, o Granito Seringa se enquadra no subtipo $\mathrm{A}_{2}$ (Fig. 10D), sugerindo fonte crustal para o mesmo.

As variáveis geoquímicas e petrogenéticas dos granitos tipo A são assuntos controversos. Os granitos

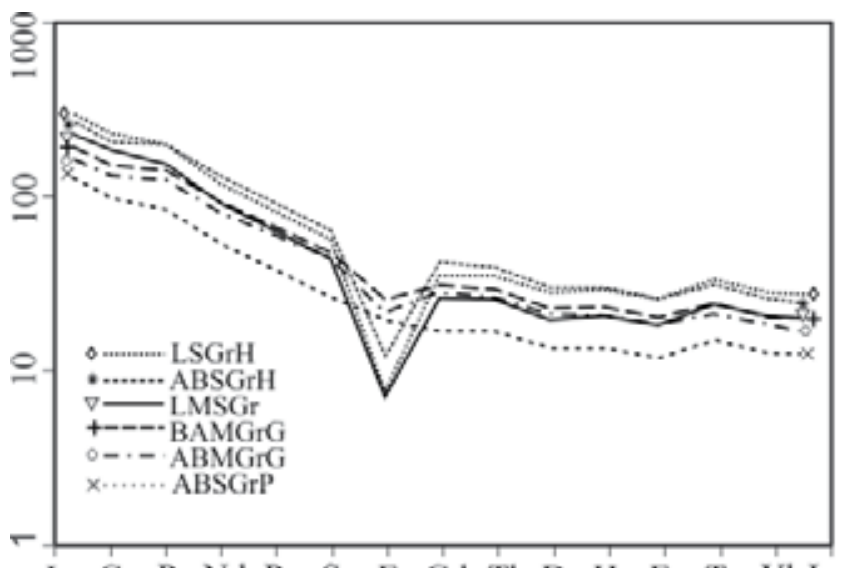

La Ce Pr Nd Pm Sm Eu Gd Tb Dy Ho Er Tm YbLu

Figura 8 - Média dos padrões de distribuição dos ETR para as amostras representativas das diversas fácies do Granito Seringa. Simbologia das fácies e suas abreviações conforme figura 6. 


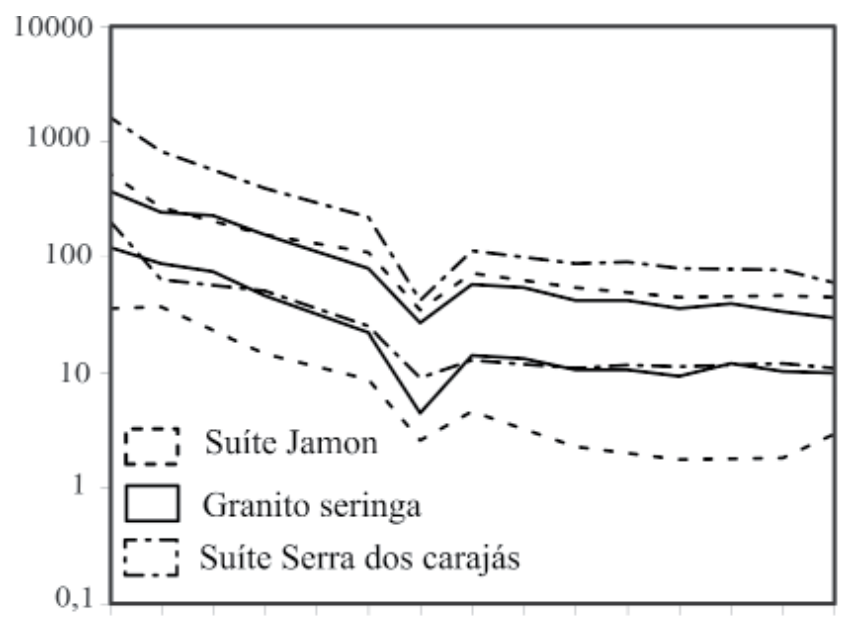

La Ce Pr Nd Pm Sm Eu Gd Tb Dy Ho Er Tm Yb Lu

Figura 9 - Diagrama comparativo dos padrões de distribuição dos ETR entre o Granito Seringa e os granitos da Suite Jamon (Redenção, Bannach, Jamon e Musa) e Suite Serra dos Carajás (Cigano e Serra dos Carajás). tipo A, da série magnetita, oxidados definidos por Anderson \& Bender (1989) são os mais problemáticos, uma vez que não seguem rigorosamente a original definição do termo e se aproximam, em alguns aspectos, dos granitos cálcico-alcalinos e granitos tipo I. Partindo dessas controvérsias, Dall'Agnol e Oliveira (2007) propuseram diagramas geoquímicos envolvendo óxidos de elementos maiores a fim de distinguir granitos tipo A de granitos cálcico-alcalinos, bem como granitos oxidados de granitos reduzidos.

Nos diagramas $\mathrm{CaO}+\mathrm{Al}_{2} \mathrm{O}_{3} \quad \mathrm{x} \quad \mathrm{CaO} /$ $\left(\mathrm{FeOt}+\mathrm{MgO}+\mathrm{TiO}_{2}\right)$ (Fig. $\left.11 \mathrm{~A}\right)$ e $\mathrm{Al}_{2} \mathrm{O}_{3} \quad \mathrm{x} \quad \mathrm{CaO} /$ $\left(\mathrm{FeOt}+\mathrm{MgO}+\mathrm{TiO}_{2}\right)$ (Fig. 11B) o Granito Seringa plota dominantemente no campo dos granitos Tipo A. Nos diagramas $\mathrm{Al}_{2} \mathrm{O}_{3} \times \mathrm{FeOt} /(\mathrm{FeOt}+\mathrm{MgO})$ (Fig. 11C) e $\mathrm{Al}_{2} \mathrm{O}_{3} /\left(\mathrm{K}_{2} \mathrm{O} / \mathrm{Na}_{2} \mathrm{O}\right) \times \mathrm{FeOt} /(\mathrm{FeOt}+\mathrm{MgO})$ (Fig. 11D) nota-se que o mesmo apresenta comportamento duplo, com as rochas monzograníticas incidindo no campo dos granito tipo A oxidado e as rochas sienograníticas no campo dos granitos tipo A reduzido.
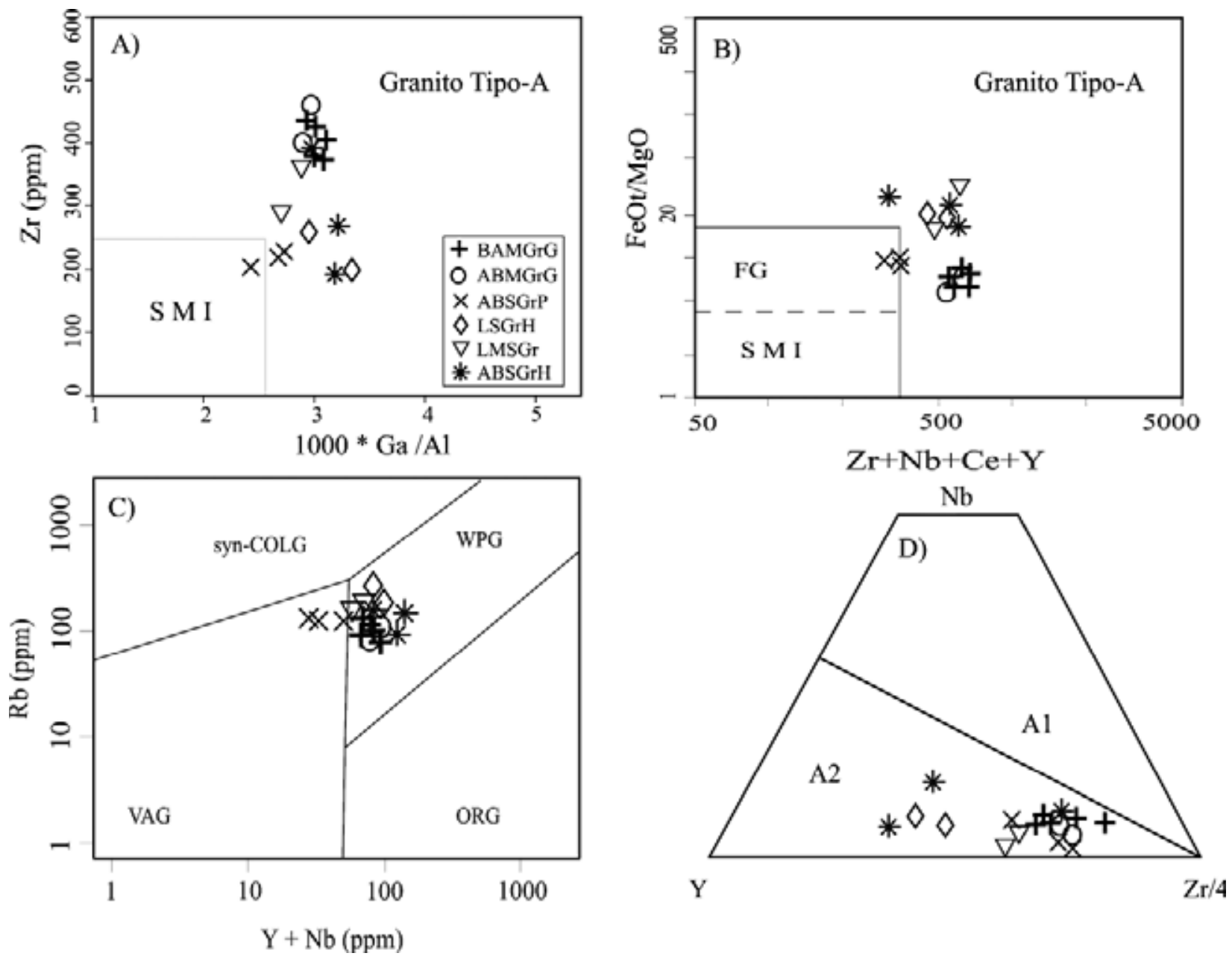

Figura 10 - Diagramas de elementos traços das rochas do Granito Seringa. A) diagrama Ga/Al $x \mathrm{Zr}$ (Whalen et al. 1987). B) diagrama $\mathrm{Zr}+\mathrm{Nb}+\mathrm{Ce}+\mathrm{Y} x \mathrm{FeOt} / \mathrm{MgO}$ (Whalen et al. 1987). M, I e S: média dos granitos tipo I, Me S; FG: granitos félsicos fracionados. C) diagrama $Y+N b \times R b$ (Pearce et al. 1984). Campos synCOLG: Granitoides Sin-colisionais, VAG: Granitoides de Arcos Vulcânicos, ORG: Granitoides de Cadeias Oceânicas e WPG: Granitoides intraplacas. D) diagrama Y-Nb-Zr/4 de Eby (1992). 
$\mathrm{CaO} /\left(\mathrm{FeO}+\mathrm{MgO}+\mathrm{TiO}_{2}\right)$ wt. $\%$

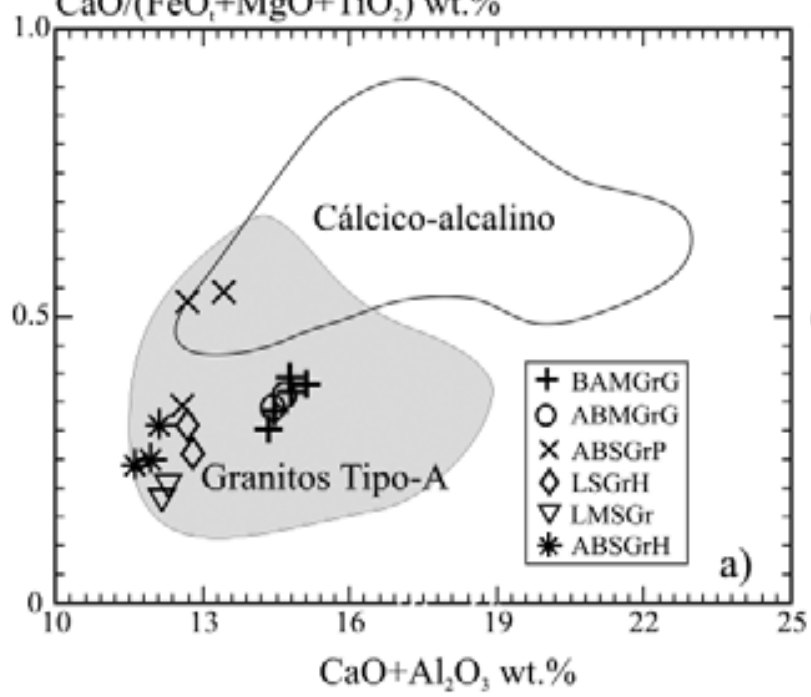

$\mathrm{FeO} /\left(\mathrm{FeO}_{1}+\mathrm{MgO}\right)$ wt. \%

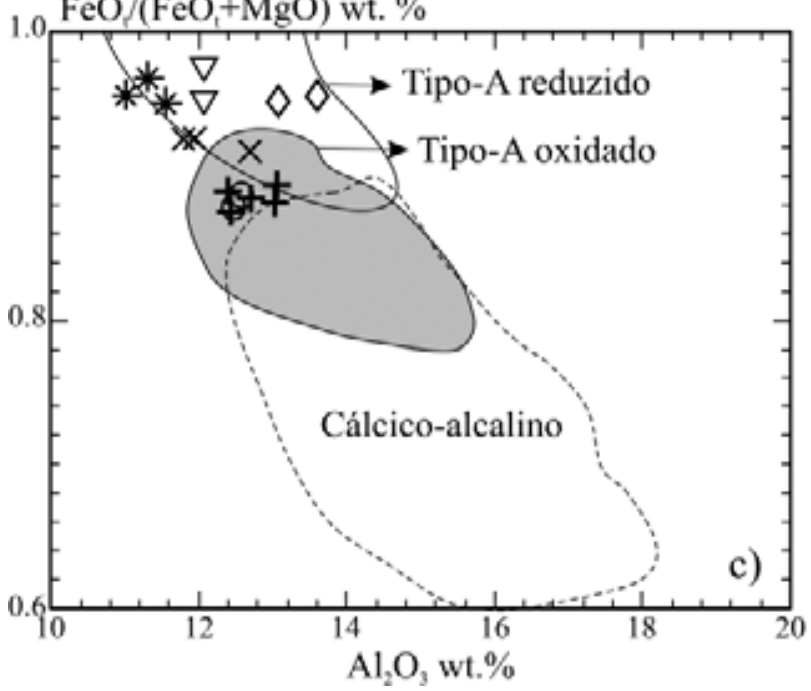

$\mathrm{CaO} /\left(\mathrm{FeO}+\mathrm{MgO}+\mathrm{TiO}_{2}\right)$ wt. $\%$

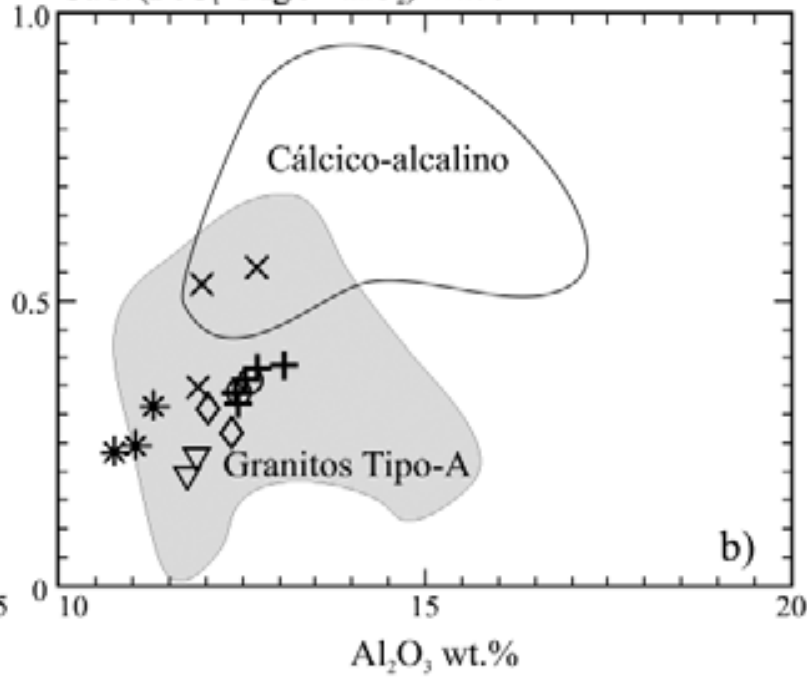

$\mathrm{FeO} /(\mathrm{FeO}+\mathrm{MgO})$ wt. $\%$

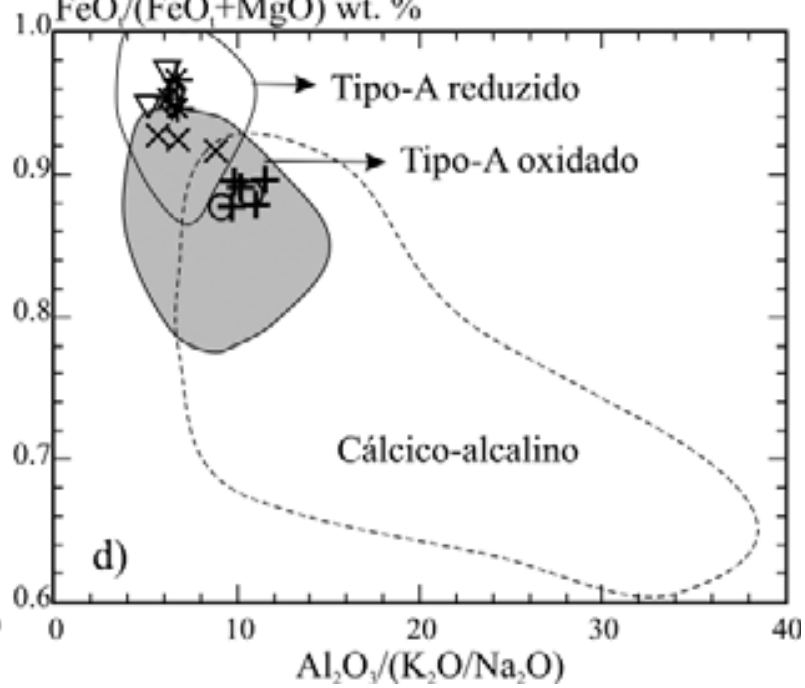

Figura 11 - Diagramas geoquímicos (modificado de Dall'Agnol \& Oliveira 2007) mostrando os campos composicionais de granitos tipo A e cálcico-alcalinos (A e B) e granitos Tipo A oxidados/reduzidos e cálcicoalcalinos (Ce D). A) $\left.\left.\mathrm{CaO} /\left(\mathrm{FeO}+\mathrm{MgO}+\mathrm{TiO}_{2}\right) \times \mathrm{CaO}+\mathrm{Al}_{2} \mathrm{O}_{3} ; \mathrm{B}\right) \mathrm{CaO} /\left(\mathrm{FeO}+\mathrm{MgO}+\mathrm{TiO}_{2}\right) \times \mathrm{Al}_{2} \mathrm{O}_{3} ; \mathrm{C}\right) \mathrm{FeO}$ $\left.(\mathrm{FeO}+\mathrm{MgO}) \times \mathrm{Al}_{2} \mathrm{O}_{3} ; \mathrm{D}\right) \mathrm{FeO} /(\mathrm{FeO}+\mathrm{MgO}) \times \mathrm{Al}_{2} \mathrm{O}_{3} /\left(\mathrm{K}_{2} \mathrm{O} / \mathrm{Na}_{2} \mathrm{O}\right)$.

CONCLUSÕES O Granito Seringa, com cerca de $2250 \mathrm{~km}^{2}$ de superfície aflorante, representa o maior batólito da PC. Ocorre sob forma subcircular e secciona unidades arqueanas diversas, formando contatos discordantes que somados aos diversos enclaves máficos, indicam evidências de seu caráter intrusivo.

A integração de dados geológicos, petrográficos e geoquímicos revelou a existência de dois grandes conjuntos de rochas, divididos em seis fácies petrográficas distintas. $\mathrm{O}$ primeiro, formado por rochas monzograníticas, é representado por bitotita-anfibólio monzogranito grosso (BAMGrG) e anfibólio-bitotita monzogranito grosso (ABMGrG) e o segundo, constituído de rochas sienograníticas, é formado por anfibólio-biotita sienogranito porfirítico (ABSGrP), leucosienogranito heterogranular (LSGH), leucomicrosienogranito (LMSGr) e anfibólio-biotita sienogranito heterogranular (ABSGrH). A distribuição espacial de suas fácies petrográficas mostra um zoneamento concêntrico, com as rochas mais ricas em máficos situadas predominantemente nas bordas do corpo e as fácies mais leucocráticas no centro.

As características petrográficas e as evidências geoquímicas não permitem supor a existência de um trend único de evolução através de diferenciação magmática para o granito Seringa, ainda que se possam caracterizar termos mais e menos evoluídos. A presença de um gap composicional entre as rochas monzograníticas e sienograníticas, evidente em todos os diagramas de variação, aponta neste sentido. Os dados petrográficos e geoquímicos sugerem que Granito Seringa pode ter sido formado por cristalização fracionada de um magma parental através de, pelo menos, três diferentes pulsos magmáticos. O primeiro estaria representado pelas rochas monzograníticas, que mostram um pequeno trend evolutivo, partindo de rochas mais ricas em 
anfibólio (BAMGrG) para rochas mais ricas em biotita (ABMGrG). O segundo teria formado as rochas sienograníticas (ABSGrP e ABSGrH) e o terceiro seria responsável pela formação de líquidos magmáticos mais evoluídos, geradores das rochas leucograníticas que são pobres em minerais máficos.

O Granito Seringa possui características metaluminosas a levemente peraluminosas e natureza subalcalina potássica. Suas razões $\mathrm{K}_{2} \mathrm{O} / \mathrm{Na}_{2} \mathrm{O}$ situadas entre 1 e 2 e $\mathrm{FeO}_{\mathrm{t}} /\left(\mathrm{FeO}_{\mathrm{t}}+\mathrm{MgO}\right)$ entre 0,87 a 0,97 são relativamente elevadas, e tendem aumentar gradualmente das rochas monzograníticas para as sienograníticas. Mostra afinidades com granitos ricos em ferro (Frost et al. 2001) e tipo A (Whalen et al. 1987), incidindo exclusivamente no campo dos granitos do subtipo A2 (Eby 1992), o que sugere fonte crustal para o mesmo, ou, com a participação de material mantélico, conforme atestado pela presença de enclaves máficos.

As variações dos teores de $\mathrm{Rb}$ são expressivas e aumentam das rochas monzograníticas para as sienograníticas, mostrando uma correlação positiva com o aumento de sílica dos ABMGrG e BAMGrG para os ABSGrP e ABSGrH, com valores mais elevados nas rochas leucograníticas. Por outro lado, $\mathrm{Sr}$ e Ba mostram correlação negativa com o aumento da sílica e acentuada diminuição dos ABSGrP e ABSGrH para as rochas leucograníticas.

As anomalias negativas de Eu são fracas nas rochas monzograníticas e moderadas a acentuadas nas sienograníticas e leucomonzograníticas, respectivamente, com exceção dos ABSGrP. Este padrão de fracionamento sugere que as rochas sienograníticas derivaram dos monzogranitos por cristalização fracionada. As concentrações mais elevadas de ETR nas rochas sienograníticas podem decorrer de um maior empobrecimento em minerais concentradores de ETR, uma vez que, durante a cristalização fracionada em sistemas graníticos, os ETR (exceto o Eu) crescem com a diferenciação.

Em linhas gerais, o Granito Seringa apresenta grandes semelhanças com os granitos da Suíte Serra dos Carajás (Barros et al. 1995, Dall'Agnol et al. 1994, Javier Rios et al. 1995). São granitos isotrópicos, intraplacas, de nível crustal elevado, tendo sido colocados numa crosta rígida cortando discordantemente suas rochas encaixantes. Em termos modais variam de monzogranitos a sienogranitos e são igualmente desprovidos de titanita magmática como fase acessória. Apresentam, ainda, superposição nos padrões de ETR e valores análogos de susceptibilidade magnética (Paiva Jr. 2009).

Com base nos dados obtidos e nas observações acima, admite-se que o Granito Seringa apresenta maiores semelhanças petrográficas, geoquímicas e de suscetibilidade magnética com as rochas da Suíte Serra dos Carajás, podendo ser enquadrado nesta importante suíte granitoide.

Agradecimentos Aos pesquisadores e alunos do Grupo de Pesquisa Petrologia de Granitoides (GPPG) pelo apoio nas diversas etapas deste trabalho, ao Prof. Roberto Dall'Agnol pela discussões, ao CNPq pela concessão de bolsa de mestrado ao primeiro autor, ao Instituto de Geociências (IG-UFPA) pelo suporte técnico e laboratorial. Este artigo é uma contribuição aos Projetos PROCAD e PRONEX/CNPq (Proj. 103/98 - Proc. 66.2103/1998-0).

\section{Referências}

Almeida J.A.C. 2005. Geologia, petrografia e geoquímica do Granito anorogênico Bannach, Terreno GranitoGreenstone de Rio Maria, PA. Dissertação de mestrado, Instituto de Geociências, Universidade Federal do Pará, Belém, $171 \mathrm{p}$.

Althoff F.J. Barbey P. Boullier A.M. 2000. 2.8-3.0 Ga plutonism and deformation in the SE Amazonian craton: the Archean granitoids of Marajoara (Carajás Mineral province, Brazil). Precambrian Research, 104:187-206.

Anderson J.L. \& Bender E.E. 1989. Nature and origin of Proterozoic A-Type granitic magmatism in the southwestern United States of America. Lithos, 23:19-52Araújo O.J.B \& Maia R.G.N. 1991. Programa de Levantamentos Geológicos Básicos do Brasil. Programa Grande Carajás. Folhas SB-22-Z-A. Estado do Pará. Brasília, DNPM/CPRM, Texto Explicativo, 164 p.

Barros C.E.M., Dall'agnol, R., Vieira, E.A.P., Magalhães, M.S., 1995. Granito Central da Serra dos Carajás: avaliação do potencial metalogenético para estanho com base em estudos da borda oeste do corpo. Boletim do Museu Paraense Emílio Goeldi Série Ciências da Terra, 7:93- 123.

Chappell B.W. \& White A.J.R. 1974. Two contrasting granite types. Pacific Geology, 8:173-174.
Collins W.J., Beams, S. D., White, A. J. R., Chappell, B. W. 1982. Nature and Origin of A-type granites with particular reference to Southeastern Australia. Contribution to Mineralogy and. Petrology, 80:189-200. CPRM 2004. Programa de Levantamentos Básicos do Brasil, Folha Araguaia (SB-22). Estado do Pará. Belém, CPRM, Relatório Técnico, 120 p.

Dall'Agnol R. \& Oliveira D.C. 2007. Oxidized, magnetiteseries, rapakivi-type granites of Carajás, Brazil: implications for classification and petrogenesis of A-type granites. Lithos 2007.

Dall'Agnol, R. 1980. Etudes sur des granites du type "Rondonian" en Amazonie Orientale et leurs transformations tardi-magmatiques. Tese de Doutorado, Labor. Geól. Petrol., Univ. Paul Sabatier, Toulouse, 348 p.

Dall'Agnol R., Lafon J.M., Macambira M.J.B. 1994. Proterozoic anorogenic magmatism in the Central Amazonian province, Amazonian Craton. Geochronological, Petrological and Geochemical aspects. Mineralogy and Petrology, 50:113-138.

Dall’Agnol R., Ramö O. T., Magalhães M. S., Macambira M. J. B. 1999a. Petrology of the anorogenic, oxidised Jamon and Musa granites, Amazonian Craton: implications for the genesis of Proterozoic, A-type Granites. Lithos, 46:431-462 
Dall'Agnol R., Scaillet B., Pichavant M. 1999c. Evolution of A-type granite magmas: an experimental study of the Lower Proterozoic Jamon Granite, eastern Amazonian craton, Brazil. Journal of Petrology, 40(11):1673-1698.

Dall'Agnol R., Teixeira N.P., Rämö O.T., Moura C.A.V., Macambira M.J.B., Oliveira D.C., 2005. Petrogenesis of the Paleoproterozoic, rapakivi, A-type granties of the Archean Carajás Metallogenic Province, Brazil. Lithos, 80:101-129.

Dall'Agnol R., Oliveira M.A., Almeida J.A.C., Althoff F.J., Leite A.A.S., Oliveira D.C., Barros C.E.M., 2006. Archean and Paleoproterozoic granitoids of the Carajás metallogenetic province, eastern Amazonian craton. In: Dall'Agnol R., Rosa-Costa L.T., Klein E.L. (eds.) Symposium on Magmatism, Crustal Evolution, and Metallogenesis of the Amazonian Craton, Abstracts Volume and Field Trips Guide. Belém, PRONEXUFPA/ SBG-NO, $150 \mathrm{p}$.

Debon F., Le Fort P., Sabaté P. 1988. Uma classificação químico-mineralógica das rochas plutônicas comuns e suas associações, método e aplicações. Revista Brasileira de Geociências, 18(2):122-133.

DOCEGEO (Rio Doce Geologia e Mineração - Distrito Amazônia) 1988. Revisão litoestratigráfica da Província Mineral de Carajás, Pará. In: SBG, Cong. Bras. Geol., 35, Anexos, p. 11-54.

Eby G.N. 1992. Chemical subdivision of the A-type granitoids: petrogenetic and tectonic implications. Geology, 20:641-644.

Frost B.R, Barnes C.G., Collins W.J., Arculus R.J, Ellis D.J, Frost C.D. 2001. A geochemical classification for granitic rocks. Journal of Petrology, 40:261-293.

Ishihara S. 1981. The granitoid series and mineralization. Economic Geology, 75th Anniv:458-484.

Javier Rios F., Villas R.N., Dall'agnol R. 1995. O Granito Serra dos Carajás: fácies petrográficas e avaliação do potencial metalogenético para estanho no setor norte. Revista Brasileira de Geociências, 25:20-31.

King P.L. White A.J.R.; Chapell B.W.; Allen C.M. 1997. Characterization and origin of aluminous A-type granites from the Lachlan Fold Belt, southeastern Australia, $J$. Petrol., 38:371-391.

Leite A. A. S. 2001. Geoquímica, petrogênese e evolução estrutural dos granitoides arqueanos da região de Xinguara, SE do Cráton Amazônico. Tese de doutorado, Centro de Geociências, Universidade Federal do Pará, Belém, $330 \mathrm{p}$.

Leite A.A.S., Dall'agnol R., Macambira M.J.B., Althoff F.J. 2004. Geologia e geocronologia dos granitoides arqueanos da região de Xinguara e suas implicações na evolução do Terreno Granito-Greenstone de Rio Maria, Cráton Amazônico. Revista Brasileira de Geociências, 34(4):447-458.

Le Maitre R.W. 2002. A classification of igneous rocks and glossary of terms. 2.ed., Cambridge, Cambridge University Press, 193 p.

Loiselle M.C., Wones D.R. 1979. Characteristics and origin of anorogenic granites. Geological Society of America Abstracts with Programs, 11:468.

Macambira M.J.B., Lafon J.M. 1995. Geocronologia da Província Mineral de Carajás; Síntese dos dados e novos desafios. Boletim do Museu Paraense Emílio Goeldi Série Ciências da Terra, 7:263-287.

Marre J. 1982. Methodes d'analyse structural des granitoids. In: Bureau dès Recherche Géologiques et Minières (ed.) Manuels \& Methodes. Orléans, BRGM, 128 p..

Nakamura N. 1974. Determination of REE, Ba, Fe, Mg, $\mathrm{Na}$ and $\mathrm{K}$ in carbonaceous and ordinary chondrites. Geochemical and Cosmochemical Acta, 38:757-775.

Oliveira D.C., Dall'agnol R., Barros C.E.M., Figueiredo M.A.B.M. 2002. Petrologia magnética do Granito Paleoproterozóico Redenção, SE do Cráton Amazônico. In: Klein E.L., Vasquez M.L., Rosa-Costa L.T. (eds.) Contribuições à Geologia da Amazônia. Belém, Sociedade Brasileira de Geologia Núcleo Norte, p. 115-132.

Oliveira M.A., Dall'agnol R., Althoff F. 2006. Petrografia e Geoquímica do Granodiorito Rio Maria da Região de Bannach e Comparações com as demais ocorrências no Terreno Granito-Greenstone de Rio Maria - Pará, Revista Brasileira de Geologia, 36(2):313-326.

Oliveira M.A., Dall'Agnol R., Althoff F.J., Leite A.A.S. 2009. Mesoarchean sanukitoid rocks of the Rio Maria Granite-Greenstone Terrane, Amazonian craton Brazil. Journal of South American Earth Science, 27:146-160.

Paiva Jr A.L. 2009. Geologia, petrografia, geocronologia e geoquímica do Granito Anorogênico Seringa, Província Mineral de Carajás, SSE do Pará. Dissertação de Mestrado, Instituto de Geociências, Universidade Federal do Pará, Belém, 123 p.

Pearce J.A, Harris N.B.W, Tindle A.G. 1984. Trace element discrimination diagrams for the tectonic interpretation of granitic rocks. J. Petrology, 25:956-983.

Pimentel M.M., Machado N. 1994. Geocronologia U-Pb dos Terrenos granito-greenstone de Rio Maria, Pará. In: SBG, Congresso Brasileiro de Geologia, 38, Boletim de Resumos Expandidos, p. 390-391.

Pitcher W.S. \& Berger A.R. 1972. The controls of contact metamorphism. In: Pitcher W.S. \& Beger A.R. (eds.) The geology of Donegal: a study of granite emplacement and unroofing. New York, John Wiley \& Sons, p. 302-327.

Shand S.J. 1951. Eruptive rocks their genesis, composition, classification and their relation to ore deposit. 4ed. London, J. Wiley, 488 p.

Silva G.G., Lima M.I.C., Andrade A.R.F., Issler R.S., Guimarães G. 1974. Geologia das folhas SB-22 Araguaia e parte da SC-22 Tocantins. Rio de Janeiro, DNPM, Projeto RADAMBRASIL 4, 143 p.

Taylor S.R. 1965. The application of trace element data to problems in petrology. In: AHRENS L.H., RANKAMA K., RUNCON S.K. (eds.) Physics And Chemistry Of The Earth. London, Pergamon Press, p. 133-213.

Texeira N. P., Bettencourt J.S., Dall'Agol R., Moura C.A.V., Fernandes C.M.D., Pinho S.C.C.P. 2005. Geoquímica dos granitos paleoproterozóicos da Suíte granítica Velho Guilherme, Província Estanífera do Sul do Pará. Revista Brasileira de Geociências, 35(2):217-226.

Tuttle O.F. \& Bowen N.L. 1958. Origin Of Granite In The Light Of Experimental Studies In The System $\mathrm{NaAlSi}_{3} \mathrm{O}_{8}-\mathrm{KAlSi}_{3} \mathrm{O}_{8}-\mathrm{SiO}_{2}-\mathrm{H}_{2} \mathrm{O}$. [S1:S.N.]. Geological Society Of America Memoir, 74:1-153 
Wedepohl K.H. 1970. Rubidium. In: Wedepohl K.H. (ed.) Handbook of geochemistry. Berlim, Springer-Verlag, p. 37-B-37-N.

Whalen J.W., Currie K.L., Chappel B.W. 1987. A-type granites: geochemical characteristics, discrimination and petrogenesis. Contribution to Mineralogy and Petrology, 95:407-419.
White A.J.R. 1979. Sources of granitic magmas. Geological Society of America Abstracts with Programs, 11(7):539.

Manuscrito ID 14752 Submetido em 10 de julho de 2009 Aceito em 03 de outubro de 2011 